Journal of Al Azhar University Engineering Sector

Vol. 14, No. 52, July 2019, 1279-1303

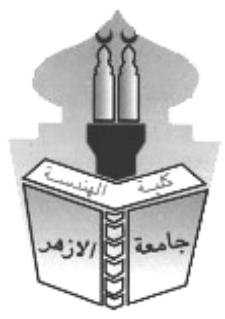

\title{
THE SMART SUSTAINABLE COMPOUNDS (STUDY CASE: THE NEW ADMINISTRATIVE CAPITAL IN EGYPT
}

\author{
Nesma Mohammed Abd el-Maksoud ${ }^{1}$ and Waleed Hussein $\mathrm{Ali}^{2}$ \\ ${ }^{1}$ Architecture Department Beni Suef University \\ ${ }^{2}$ Architecture Department, Fayoum University \\ sohanosa@gmail.com, waleedabu.mazen@gmail.com
}

\begin{abstract}
The research adopts the descriptive analytic approach. It is divided into three parts. The first part Which follows the inductive theoretical study includes the urban orientations, in the spotlight of the future Egyptian vision, through studying the sustainable development, strategy vision. This is followed by the second part which examines the new urban compounds according to the future of urbanization in Egypt, that includes establishing new capital city and Must go to study of housing sector where (housing is the consequence of establishing capitals not the aim). for the compounds' orientations from the sustainable and smart perspective, in order to reach the Smart sustainable housing criteria as one of the developmental approaches to housing sustainability in Egypt. It ends by In the third part, which includes applied analytical study and measurement of the sustainability of housing in the new urban communities (case study the third district in the new administrative city, according to measurements.
\end{abstract}

Key Words: Compounds- (Sustainable- Smart) Urban -The Administrative Capital Of Egypt.

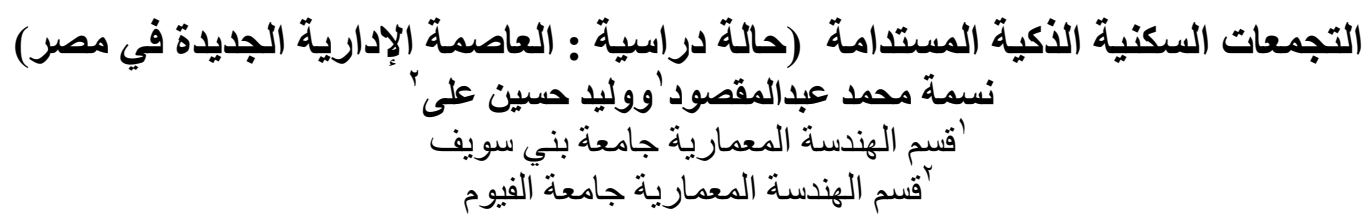

الملخص:

يعتمد البحث على المنهج الوصفي والتحليلي وينقسم الى ب اجزاء يتضمن الجزء الاوله التهول الذي يتبع الدراسة

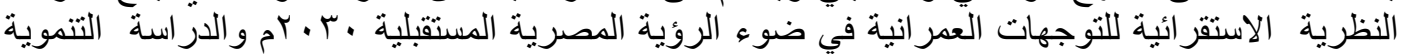

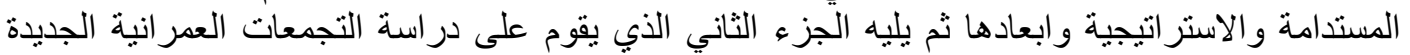

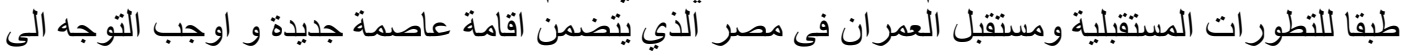

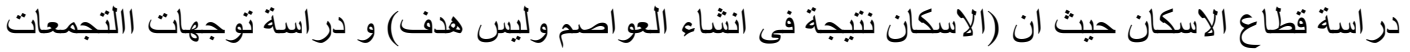

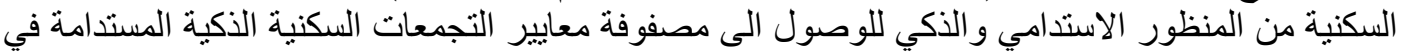

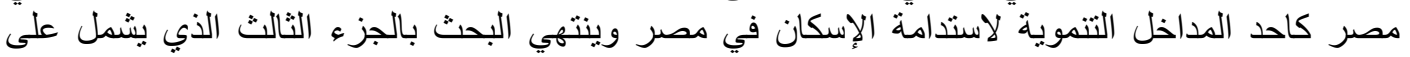
JAUES, 14, 52, 2019 
الدر اسة التحليلية التطبيقية وقياس مدي استدامة الاسكان بالتجمعات العمر انية الجديدة (حالة در اسية : الحي

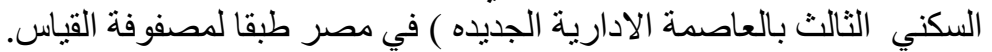

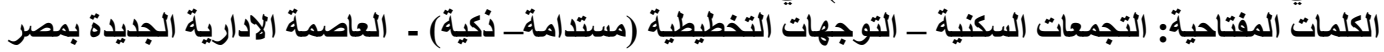
فرضية البحث: يفترض البحث ان التجمعات السكنية في مصر تحتوي على العديد من المشكلات البيئية و العمر انية وتفتقر

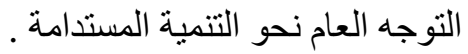
يهدف البحث البى الوصول الى مؤشرات ومعايير التجمعات السكنية الذكية المستدامة (مصفوفة قياس) كمدخل تتموي لاستدامه التجمعات السكنية في مصر فئ فئ ظل التطور التهر ات الحديثة. المقدمة: يو اجه التخطيط العمر اني بشكل عام و قطاع الإسكان بشكل خاص العديد من التحديات من أجل تحقيق التنمية

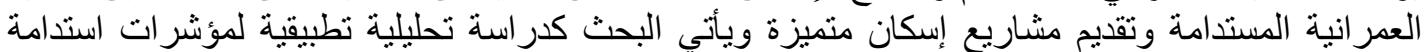

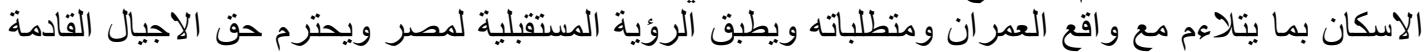

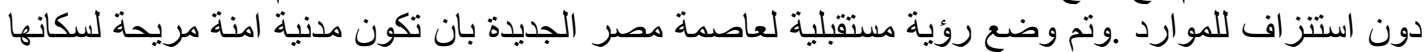

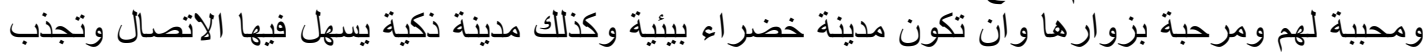

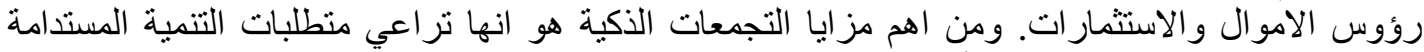

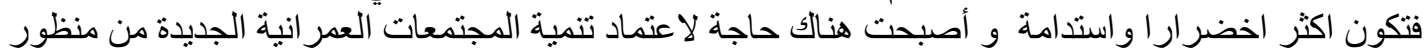
ذكي مستدام .

الكلمات المفتاحية: المركبات ـ (المستدامة ـ الأكية) الحضرية ـ العاصمة الإدارية لمصر.

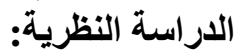

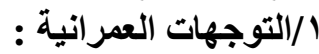
1/1 الوجهات المدن المصرانة : المصرية تبعا للاستدامة العمر انية :

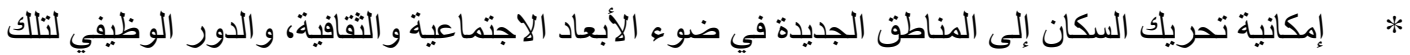

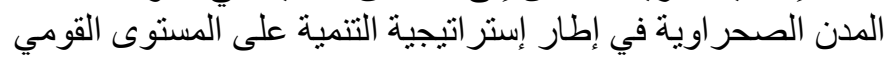

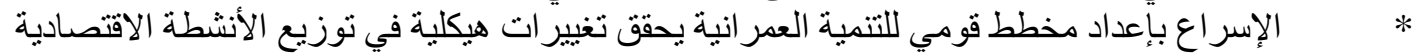

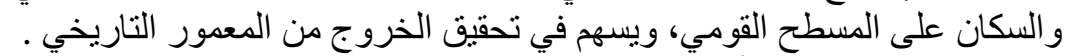

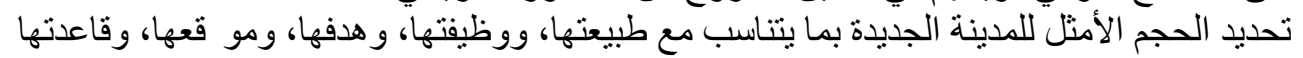

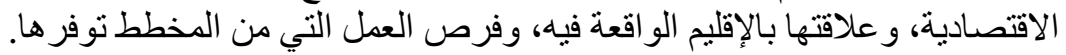

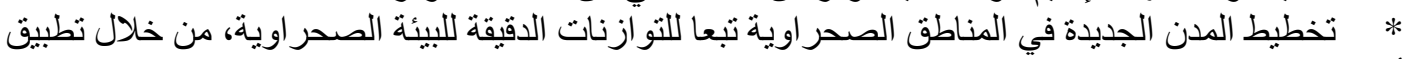

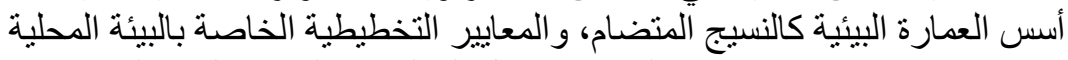

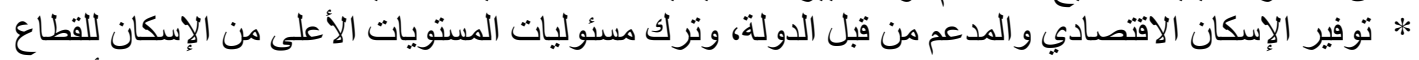

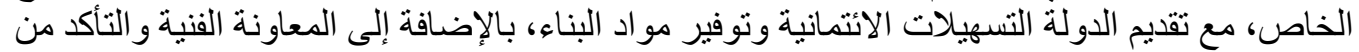

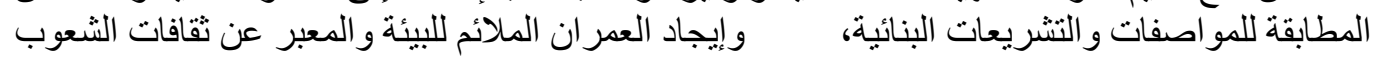

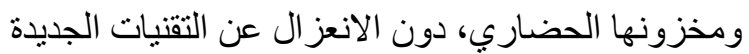

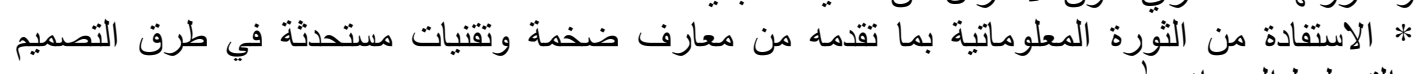
و التخطيط العمر اني.

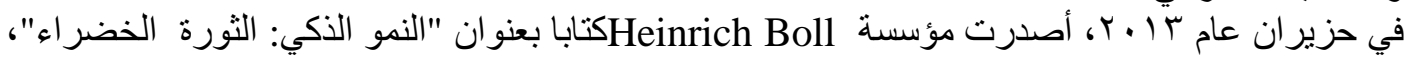

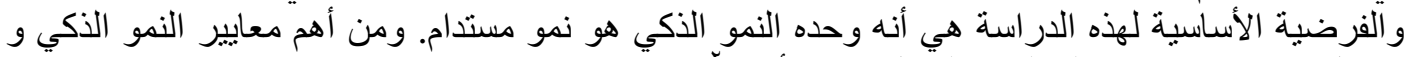

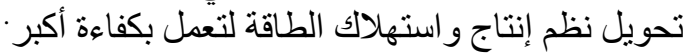


مصطلح المدينة الذكية يقصد به المكية المدينة التي تتو افر بها خدمات الاتصالات وتقنية المعلومات المتطورة .

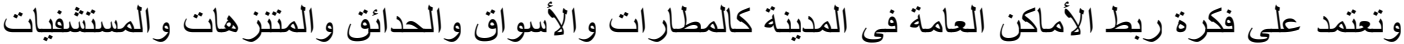

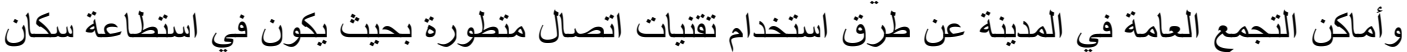

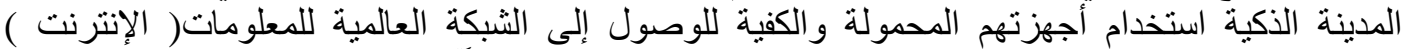

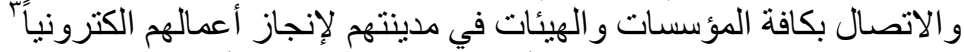

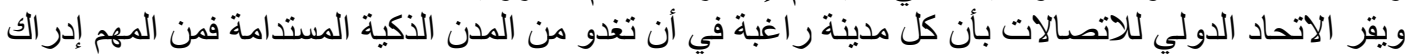

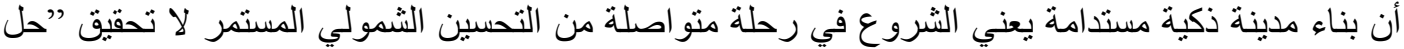

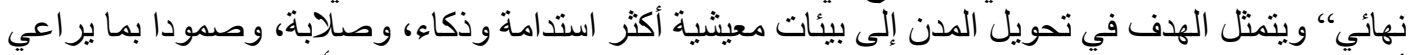

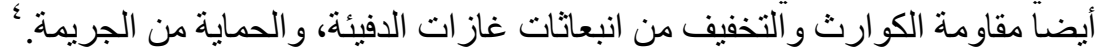

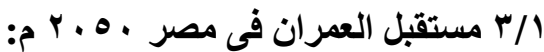

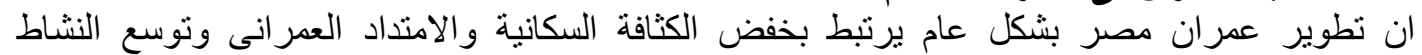

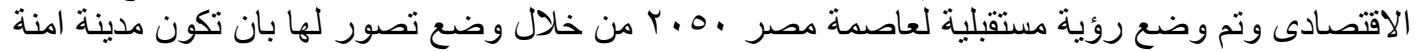

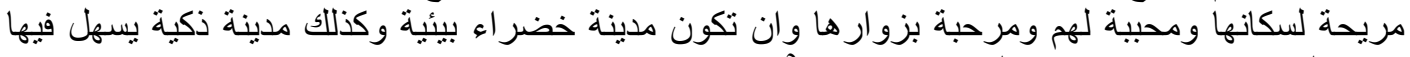

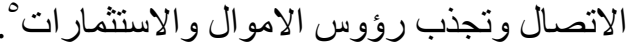

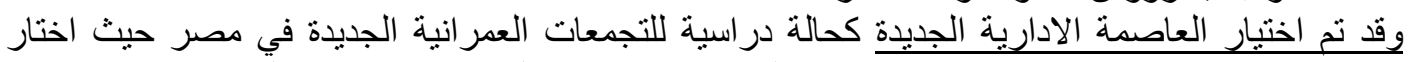

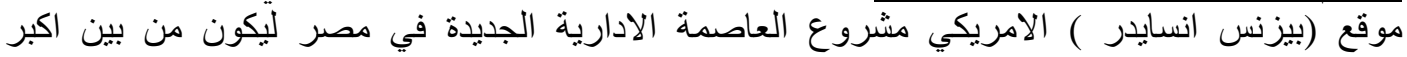

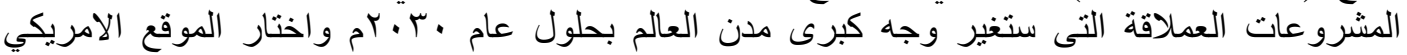

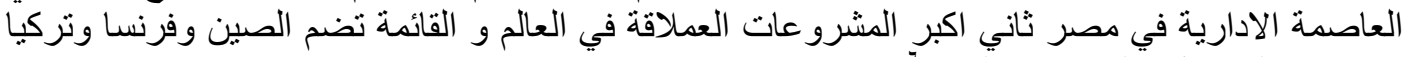

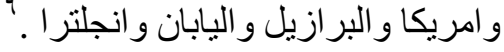

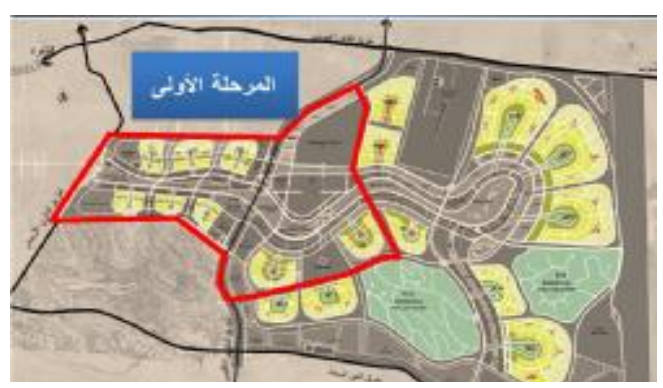

شكل (1) مخطط العاصمة الادارية الجديدة/

https://real-estate-المصدر live.blogspot.com $/ 2017 / 04 / \mathrm{blog}-$ post_12.html

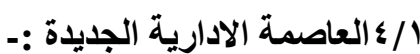

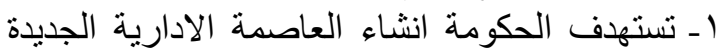

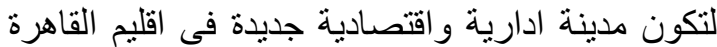

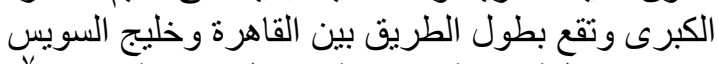

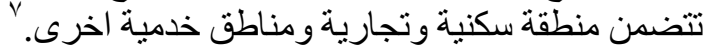

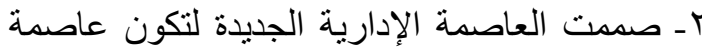

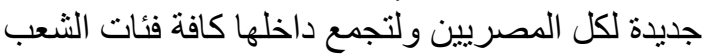
المصرى بإختلاف طبقاتهم و ومستوياتهمالإجتماعية و الإقتصادية .عاصمة ستؤسس بداية جديدة و و عظيمة

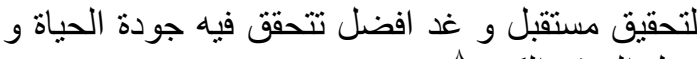

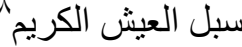

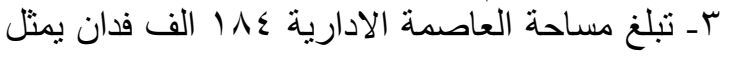




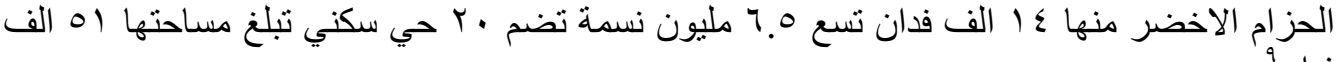
فدان ع - مشروع العاصمة الادارية الجديدة هو مشروع قومى بالاساس تتنوع عوائده الاقتصادية من نوسيع الحيز

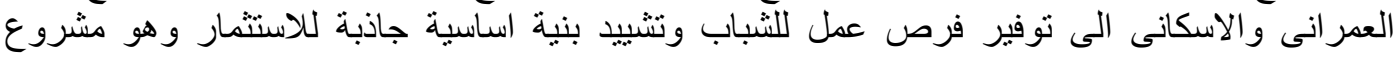

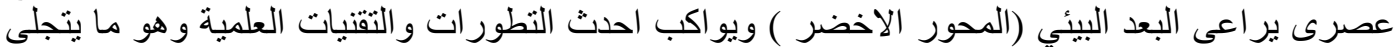

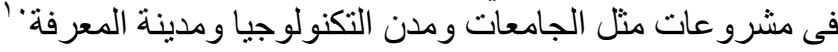

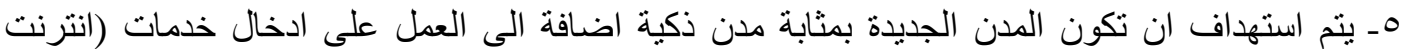

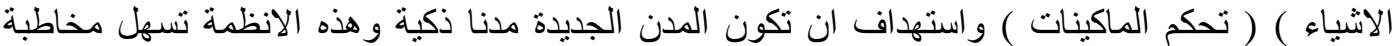

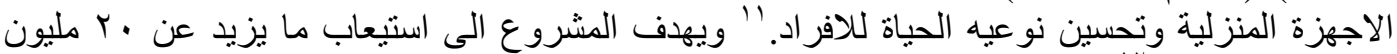

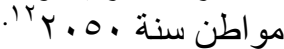
7- ان السبب ور اء انشاء العاصمة الجديدة ياتى لعدم قدرة محافظة القاهرة على استيعاب زيادات سكانية

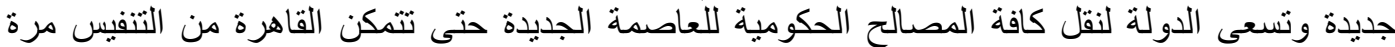

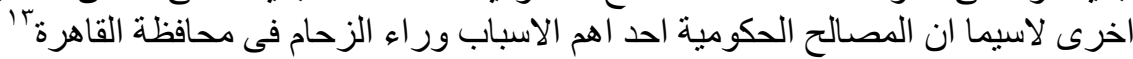

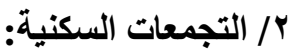

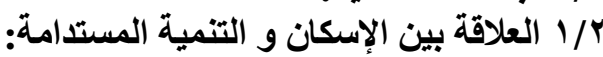

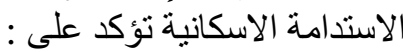
* التأكيد على مفهوم المجموعة السكنية وليس المبنى المنفرد لايجاد فضاءات تؤكد على العلاقات الاجتماعية. * التأكيد على المناخ المصغر و التكيف مع البيئة الطبيعية

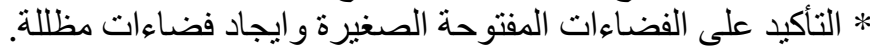

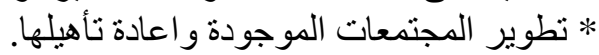
* تشكل المدن السكنية كنواة جذب عمر انية تساهم في توجيه الامتداد العمراني مع التأكيد على الهوية

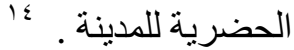
و Y مفهوم المجاورة السكنية : هي مساحة ماهولة بالسكان ضمن مجمو عة من المساكن بمر افقها العامة

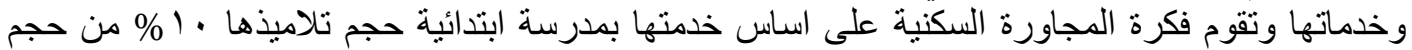

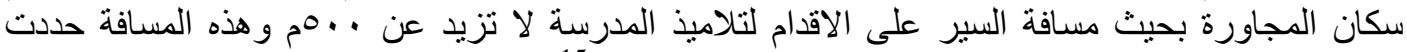
الامتداد الجغر افى للمجاورة وتمثل المجمو عة السكنية الصغرى. 15

ب/اتطور المحددات الاساسبة للمجاورة السكنية فى ضوء التوجهات التخطيطية الحديثة:

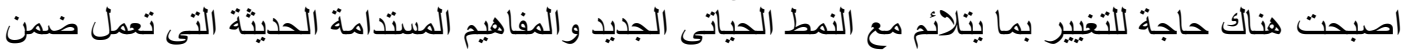

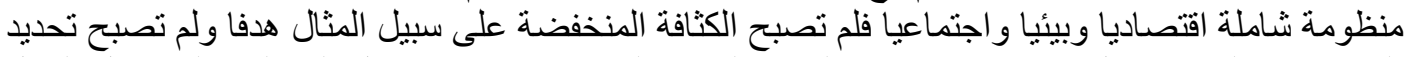
الخدمات باسلوب مستقل نمطا انما ظهرت الدو افع لزيادة الكثافة ودعم الاستعمال المختلط على سبيل المثنال 
ولكن ضمن حدود تسمح بتحقيق هذا الهدف وتعزز التفاعل الاجتماعى وهى مسافة سير التلميذ بحيث لا تزيد

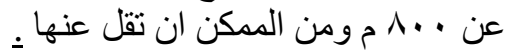

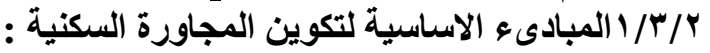

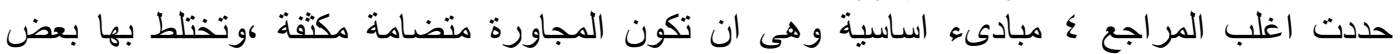

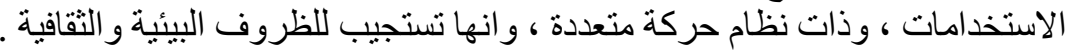

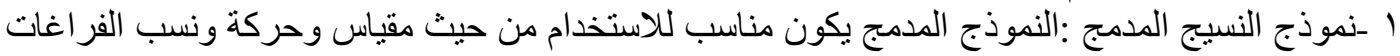

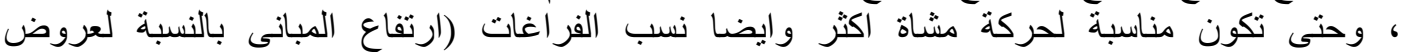

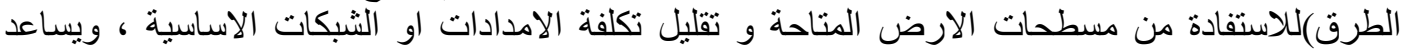

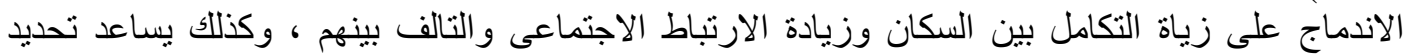

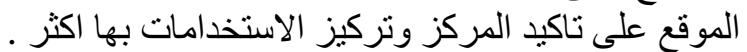

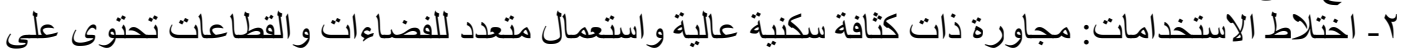

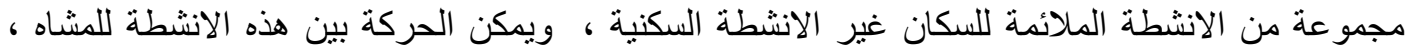

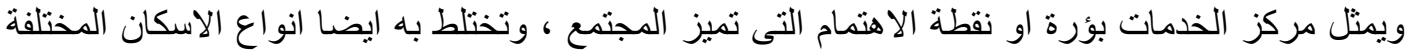

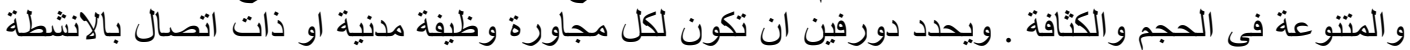
التى تخدم باقى المدينة .

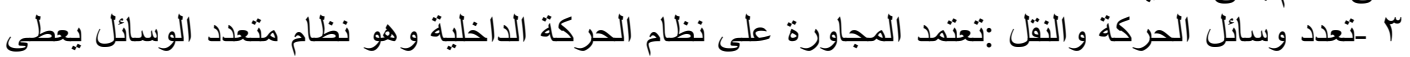

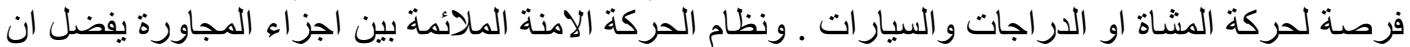

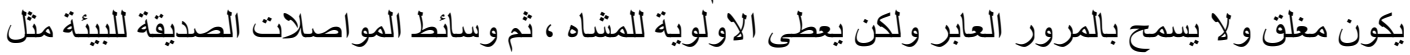

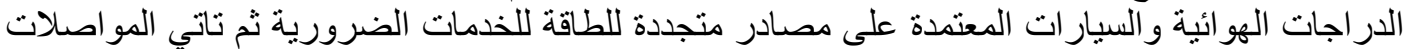

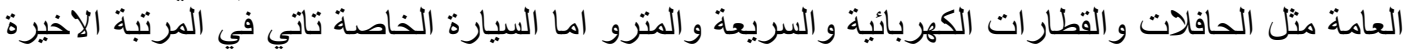

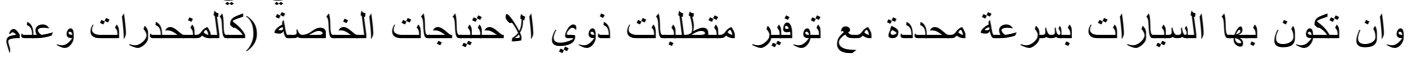
وجود درجات و وعو ائق).

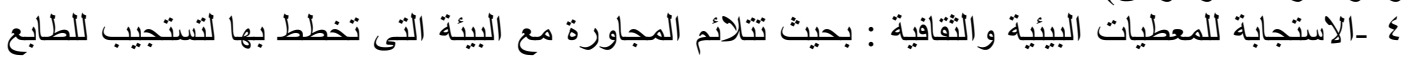

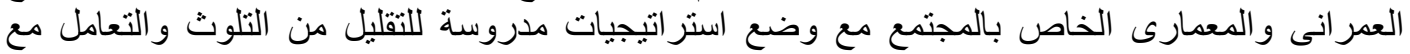

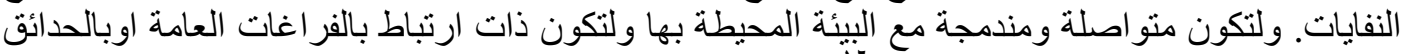

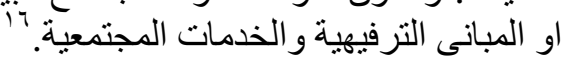

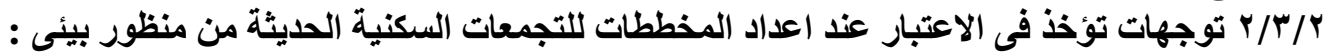

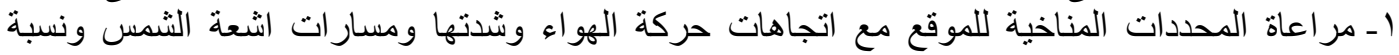

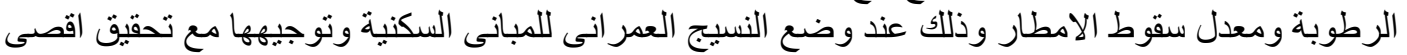

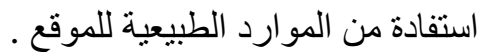

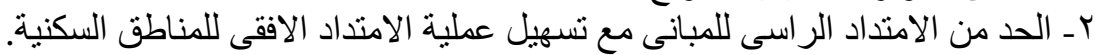

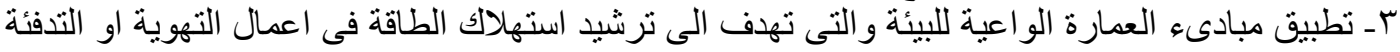

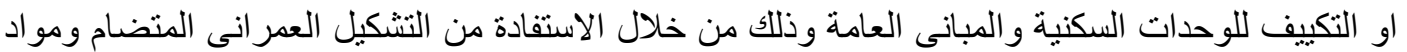

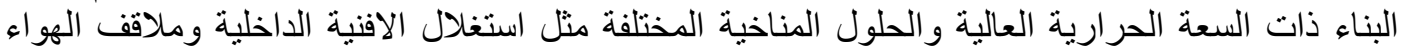

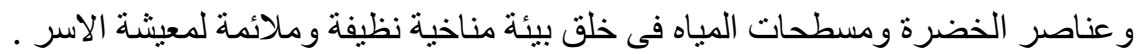

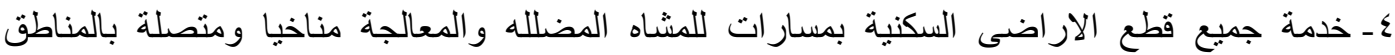

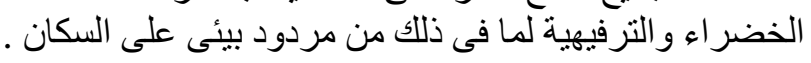


ــ تسهيل الحركة بين المناطق السكنية ومناطق الخدمة وتخطيط محاور الحركة بينهما الى اقل مسافة وذلكة

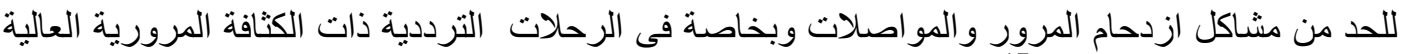

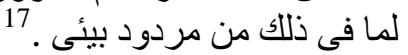

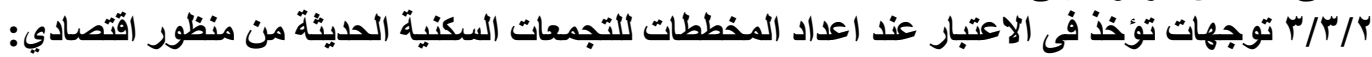

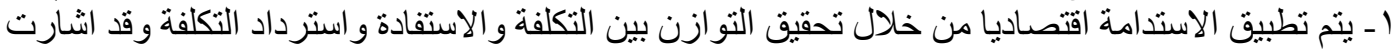

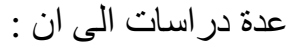

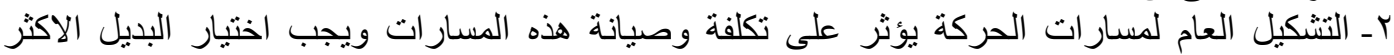

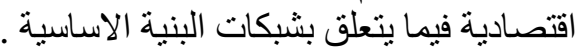

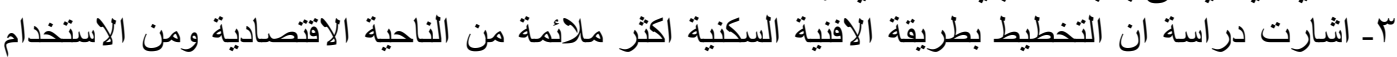
وحركة المشاة.

ع - يمثل التشكيل المتضام احد التوجهات لخفض تكاليف التنمية العمر انية للمشرو عات السكنية

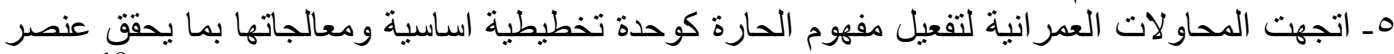

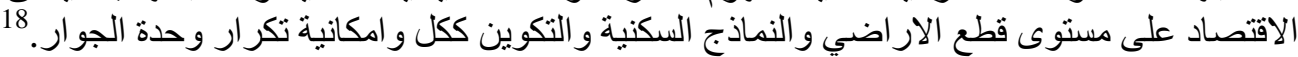

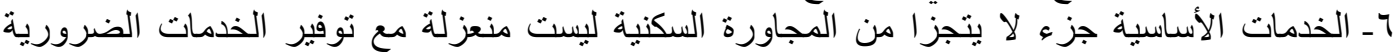

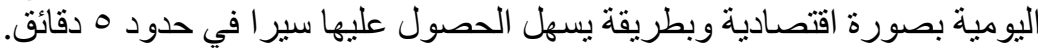

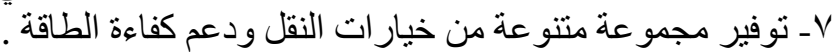

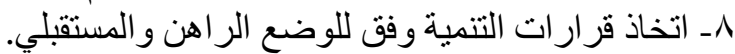

ا / / آ آ توجهات تؤخذ في الاعتبار عند اعداد المخططات للتجمعات السكنية الحديثة من منظور اجتماعي:

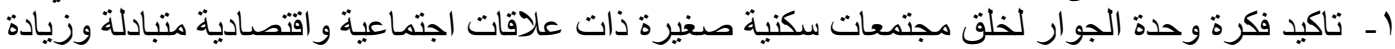

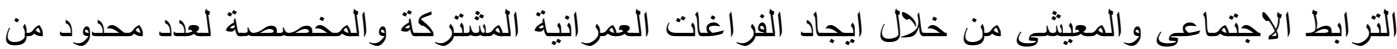

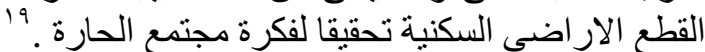

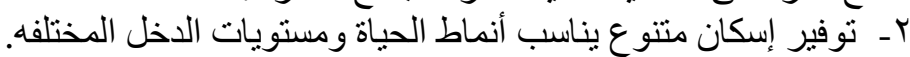

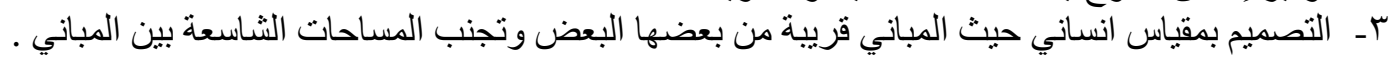
عـ تخطيط وتصميم المكان بطريقة سهلة لسهولة ادر اكة من قبل المستخدم و إمكانية استخدام المكان لُعدة

ــ ـ توفير فر اغات عامة وشبة عامة ومناطق مفتوحة تنمي الإحساس بالمكان و الأنشطة الاجتماعية.

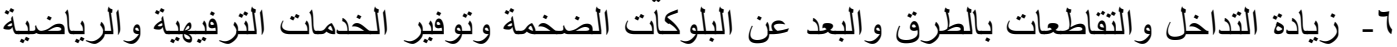
اليومية.

V- توفير عناصر الخصوصية للوحدات السكنية والتكامل بين الارتفاعات لتحقيق الخصوصية

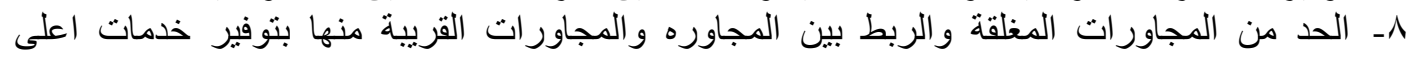

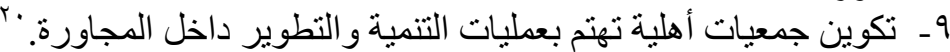

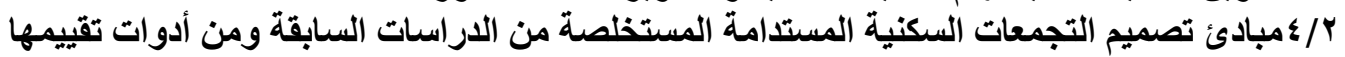
وعلاقتها بالعناصر التصنيات التصميمية:

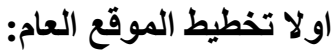
1 - حماية البيئة الطبيعية والعيط: الحياة البرية و تقييم مخاطر الفيضان مع الحفاظ على التضاريس. 


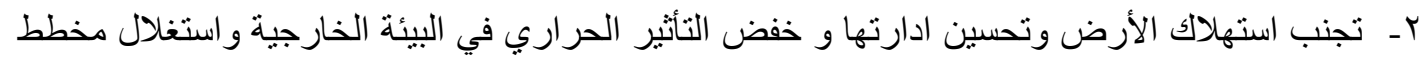

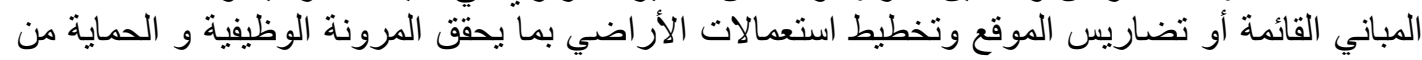

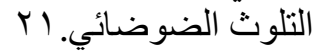

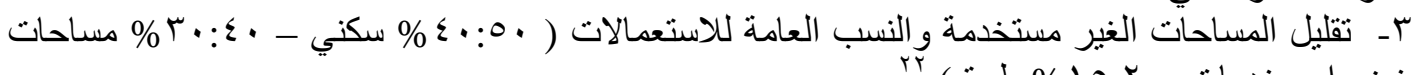

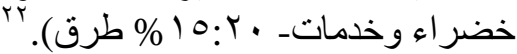

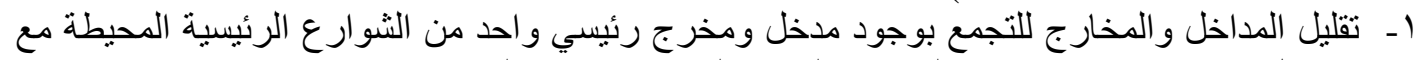

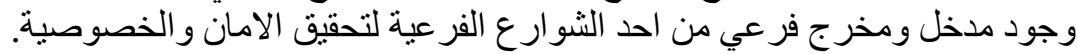

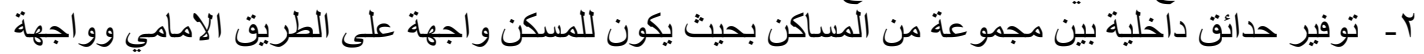

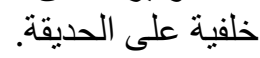
بــ اعتبار عامل الرياح في تصميم التجمع وتوجيه الطرق و المساكن باتجاه الرياح السائدة واستغلال التهوية الطبيعية في المساكن و الاماكن المفتوحة.

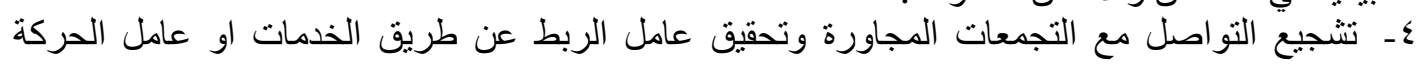

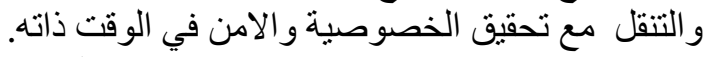

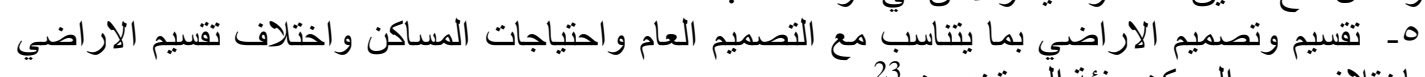
باختلاف حجم المسكن وفئة التمتيخدمين. 7 - ـ تدرج مناسب للخدمات حسب كثافة الحاجة لها (يوم- اسبو عي- شهري- سنوي) ابتداء بالمركز الخدمات

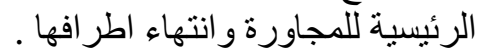

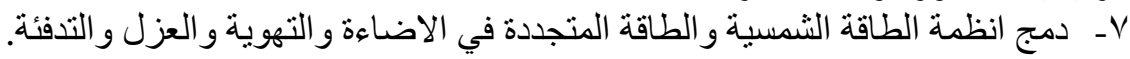

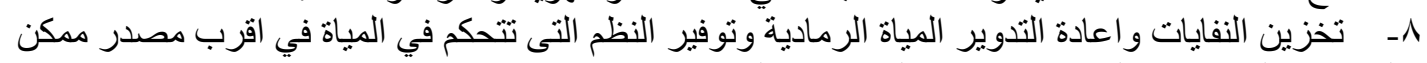

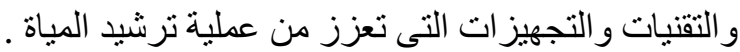

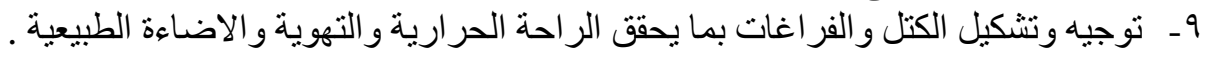

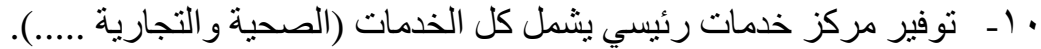

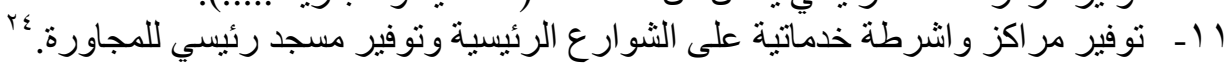

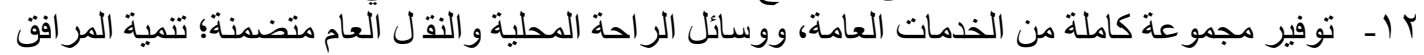

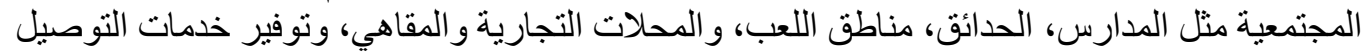

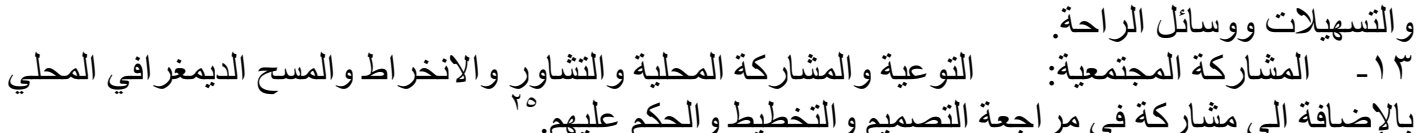

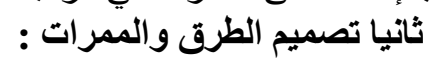

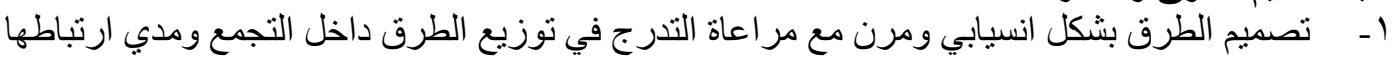
بالمداخل الرئيسية . بائرق

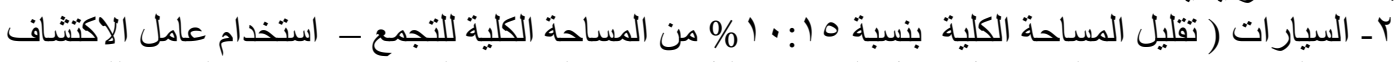

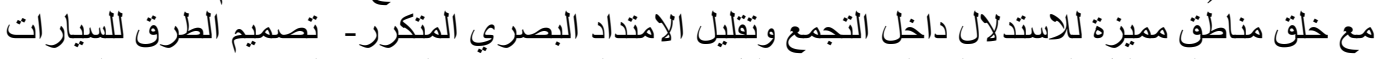
بما يساعد على تقليل السر عة الداخلية - تقليل مو اقف السيار اتلفي في المناطق السكنية ومناطق الخدمات 
و التركيز على الوصول لهذه المناطق سير ا - التشجير على جو انب الطريق كمنظر جمالى وللتظليل -

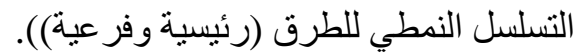

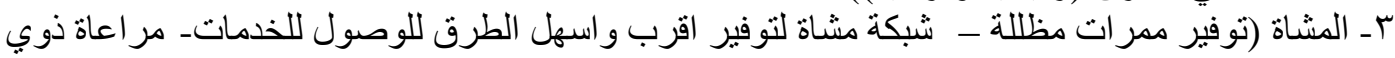

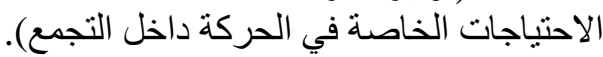

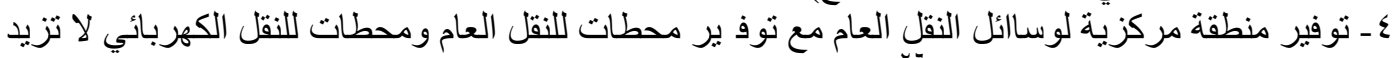

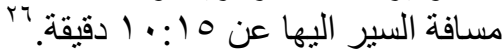

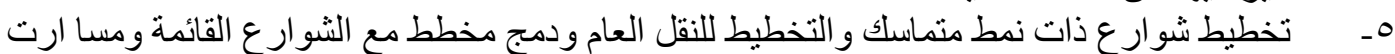

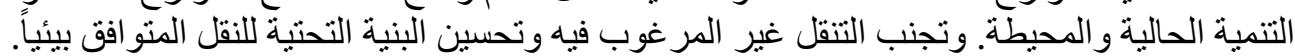

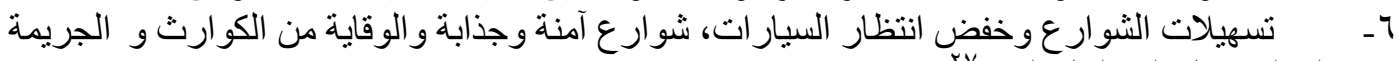

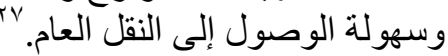

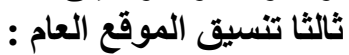

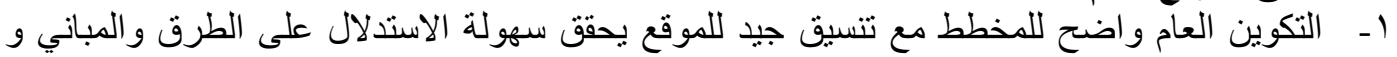
احتر ام الهوية المحلية و الحفاظ على وتحسين البناء والاثر الطبيعي وتكوين بيئة ذات كفاءة جيدة ومريحة

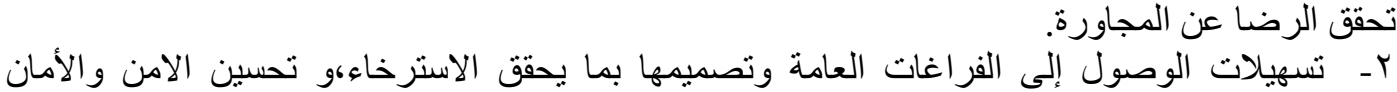

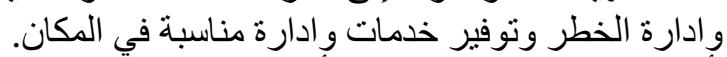

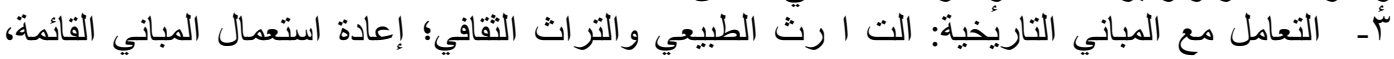

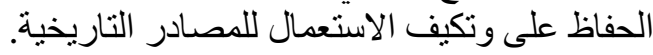

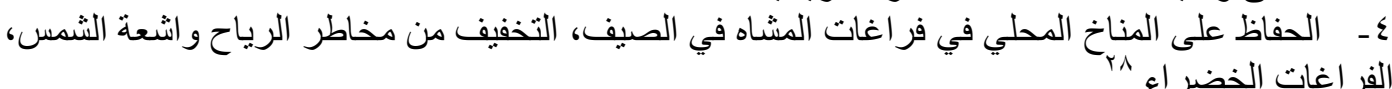

ــ ـ ـ ـوحيد النمط المعماري وتصميم المناطق المفتوحة و الطرق الداخلية مع اختلاف الحلول التصميمية.

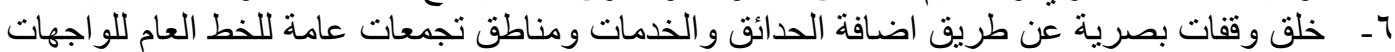
على الطرق الداخلية. - V- توفير شبكة من النسيج الاخضر و الاشجار و النباتات المتنو عة و ايجاد حدائق حضرية .

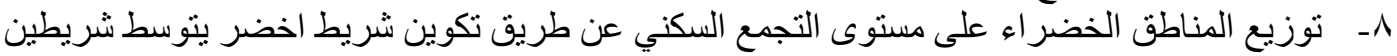

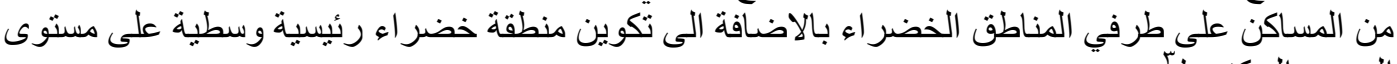
المجمع السكني. رابعا المساكن : المبكي

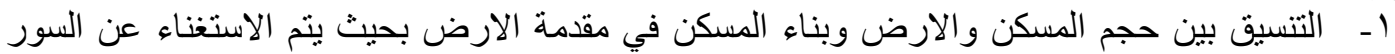
الخارجي بما يساعد في تعريف الفراغ العام بشكل افضل ويتم استغلال الارض وض بشكل اكبر يساعد على الألى التوسعة المستقبلية. r - ت تحديد اماكن مو اقف السيار ات للمسكن الو احد. r- ت توزيع المساكن حسب ارتفاعاتها. 
ع - استخدام مو اد وتقنيات تساهم في خفض التكاليف مثل ( مرونة الفر اغات وتعدد استخدماتها- الاستفادة

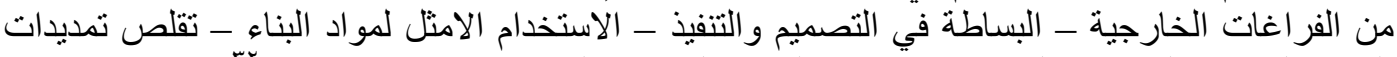

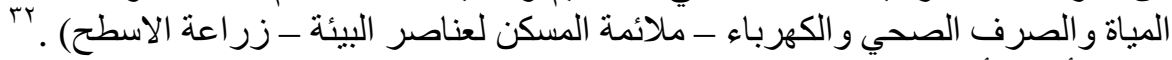

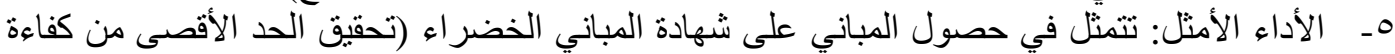

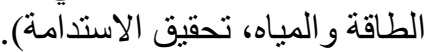

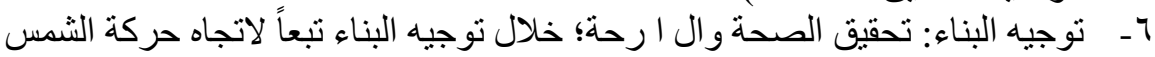

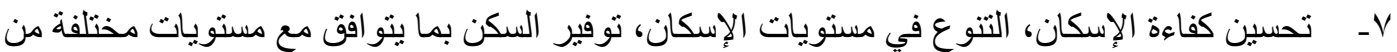

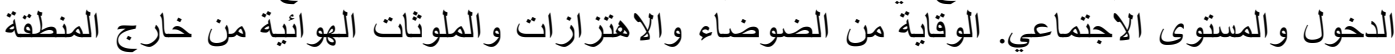
المحددة.

人- ظهورة المبنى بشكل جيد من ناحية الجوانب المعمارية.

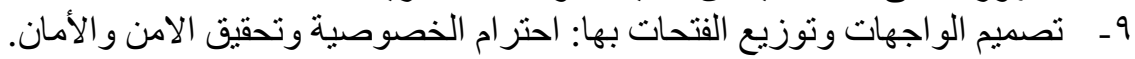

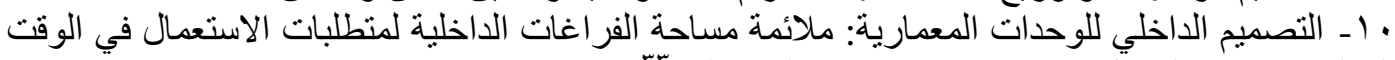

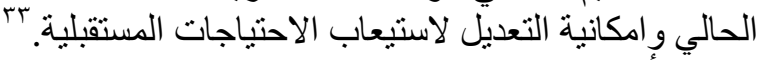

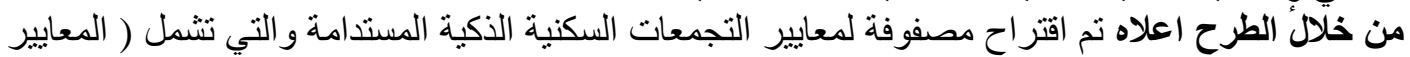

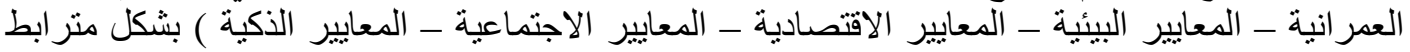

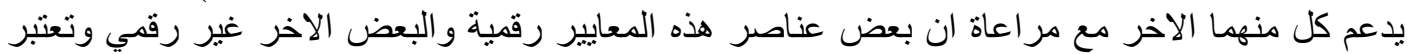

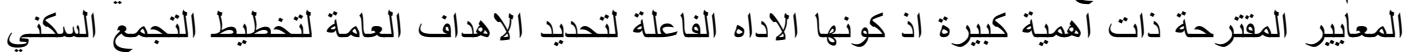

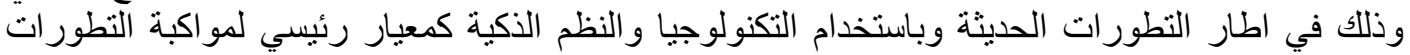

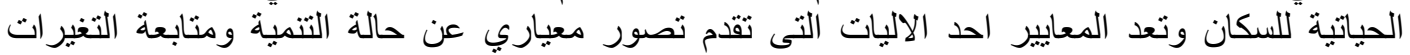

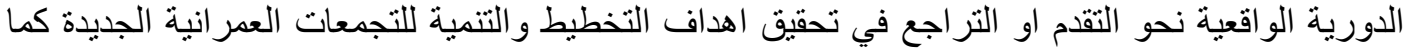

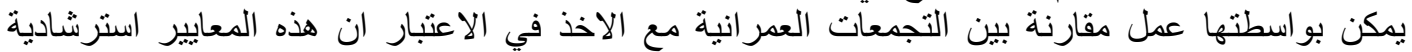

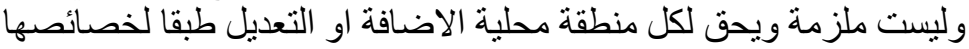

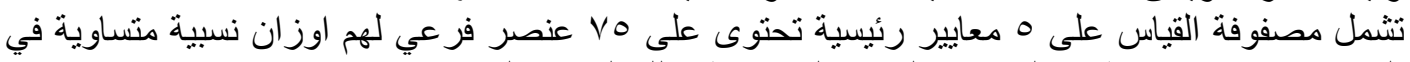

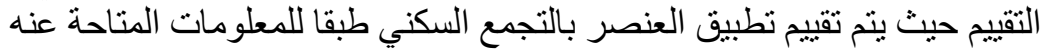
جدول( 1) نسب التقييم تبعا لمصفوفة القياس/المصدر : الباحثة المئة

\begin{tabular}{|c|c|c|c|c|}
\hline اجمالى تطبيق المعايير & نسبة تطبيق المعيار & مدي التطبيق & نسبة التطبيق & المعيار \\
\hline 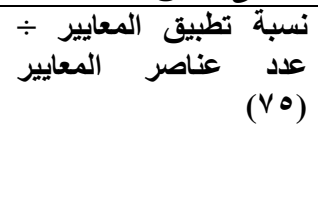 & مجاصر المعيار الواحب تطبيق & 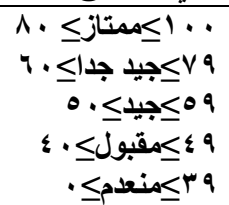 & للمبة منومات المتاحة طبة & العنصر \\
\hline
\end{tabular}

وتم تقسيم نسب التقييم السابقة اتباعا لمقاييس تقييم الهرم الاخضر المصري r/ه مصفوفة قياس تطبيق معاييز التجمعات السكنية الأكية المستدامة: 
جدول (ץ) مصفوفة قياس تطبيق معايير التجمعات السكنية الأكية المستدامة:/ المصدر : الباحثة

\begin{tabular}{|c|c|}
\hline نسبة التطبيق & ciاص الة \\
\hline 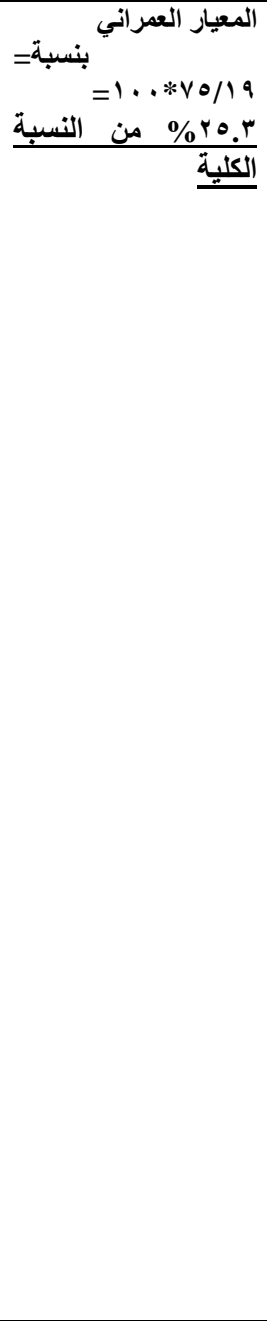 & 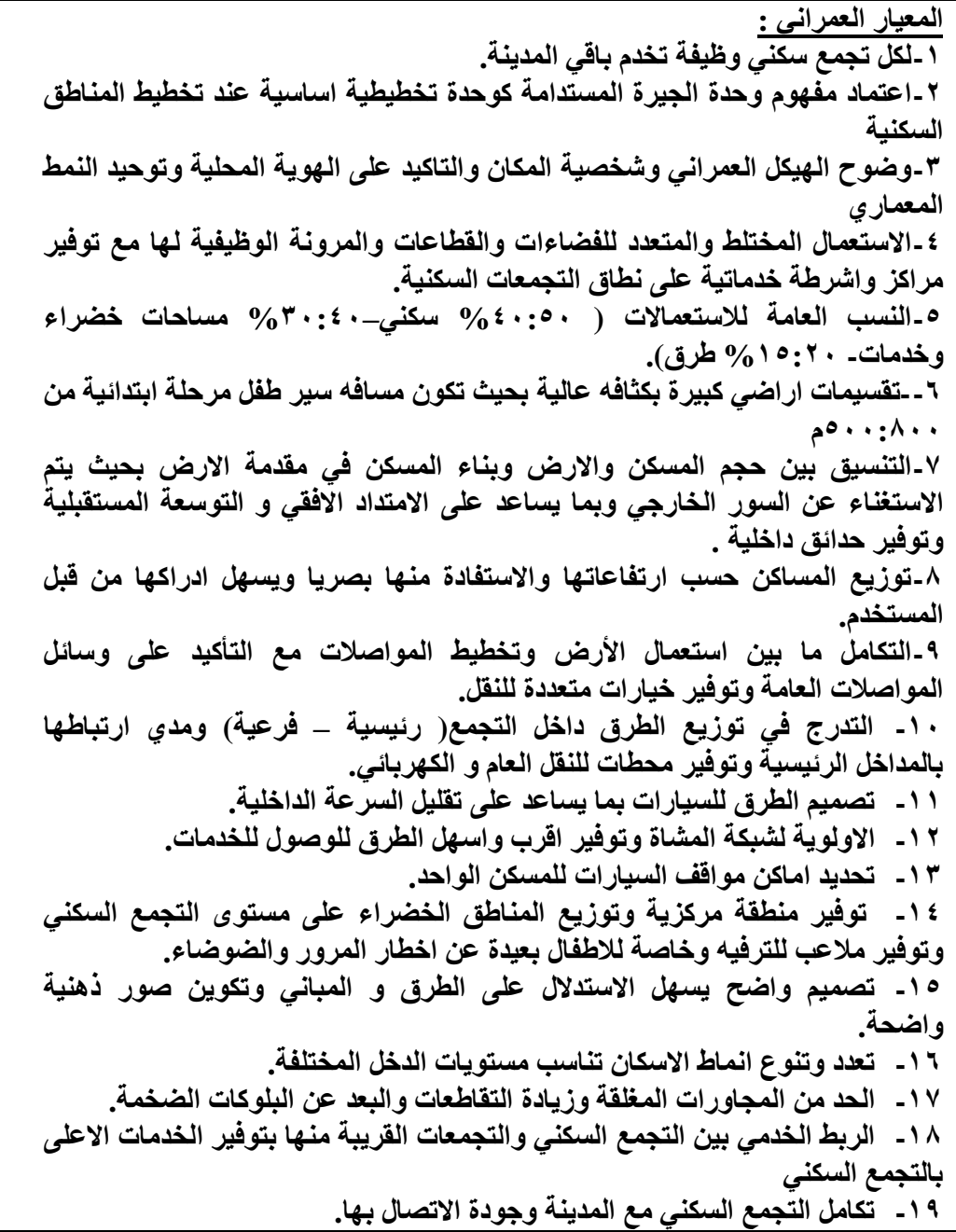 \\
\hline 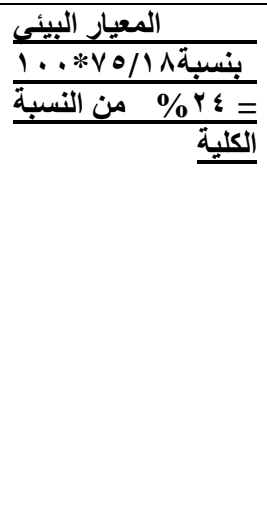 & 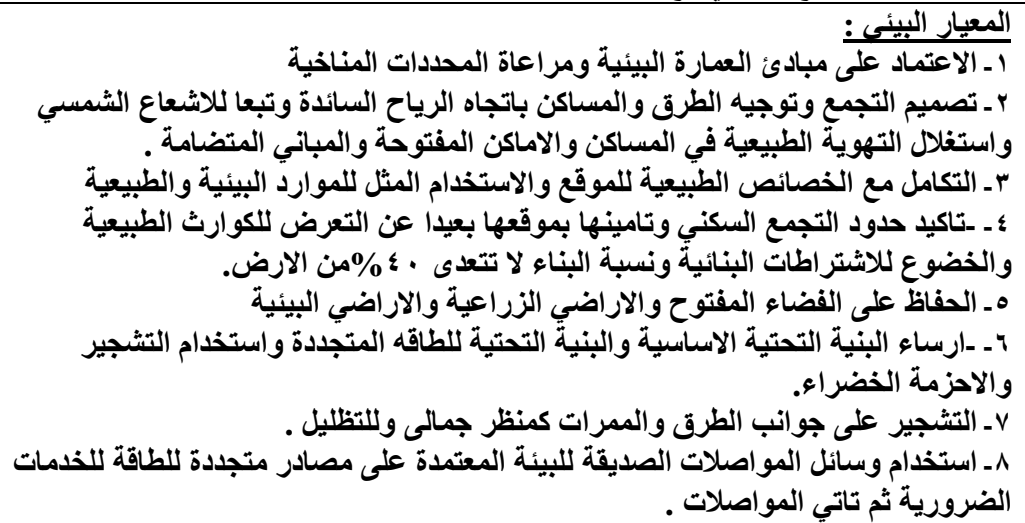 \\
\hline
\end{tabular}




\begin{tabular}{|c|c|}
\hline & 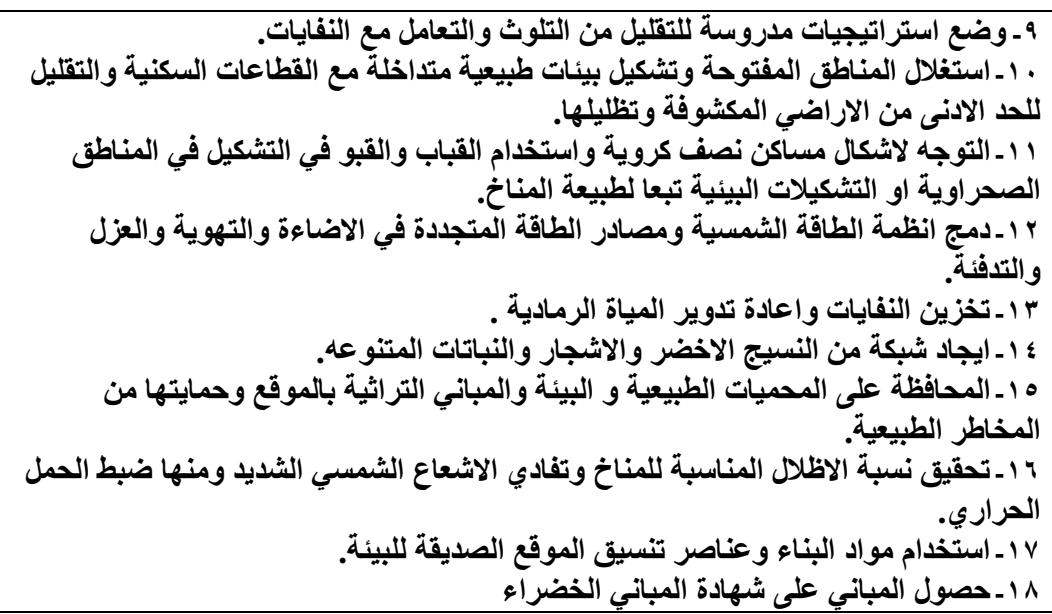 \\
\hline 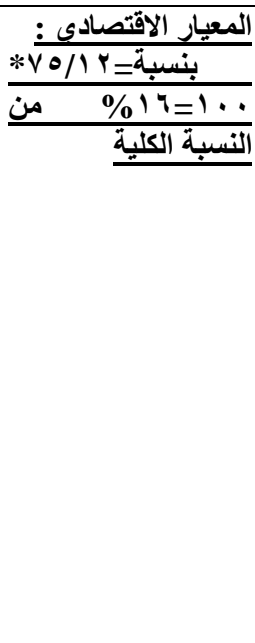 & 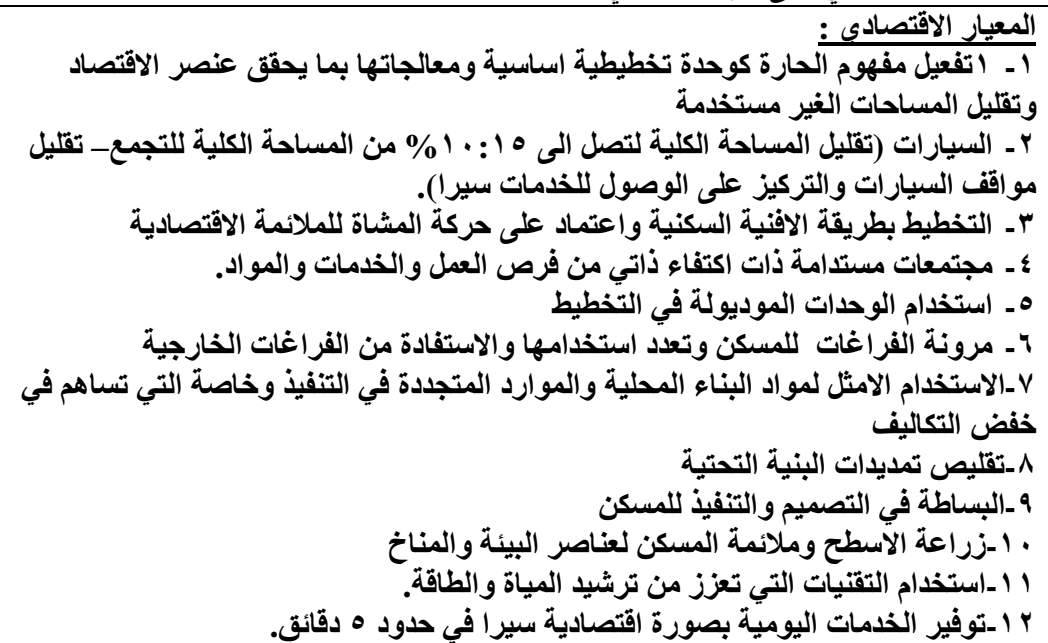 \\
\hline 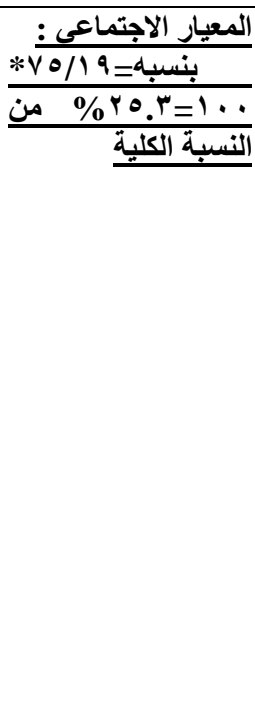 & 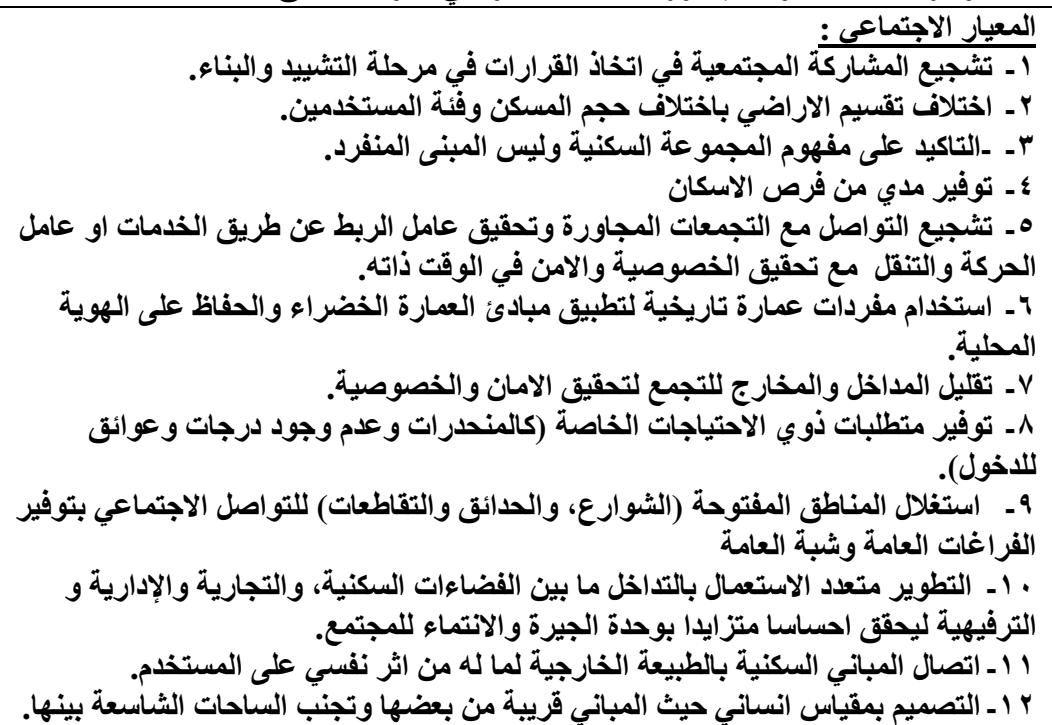 \\
\hline
\end{tabular}




\begin{tabular}{|c|c|}
\hline & 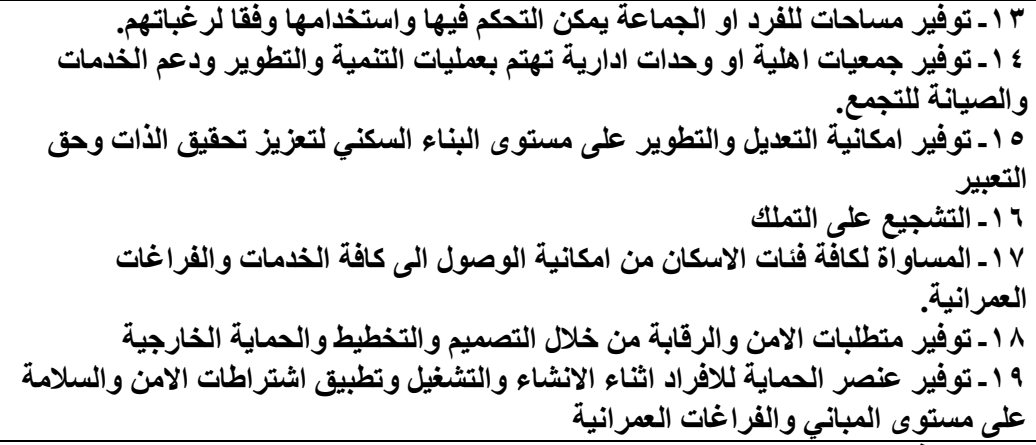 \\
\hline 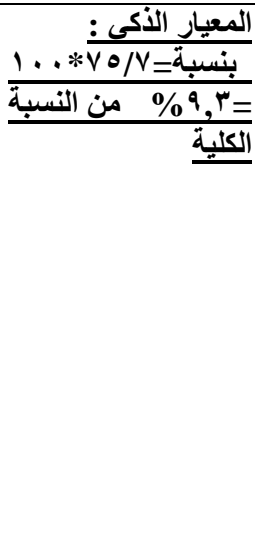 & 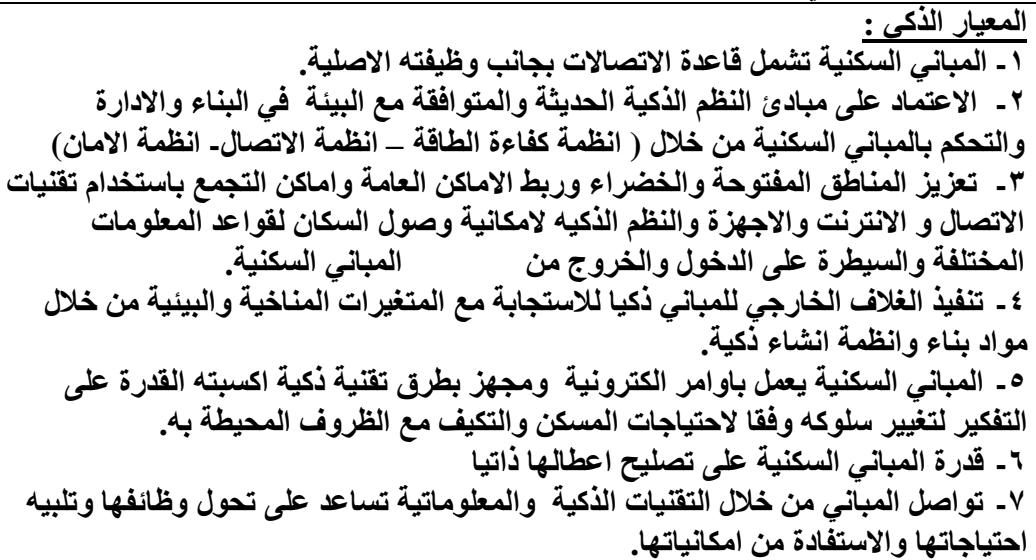 \\
\hline
\end{tabular}

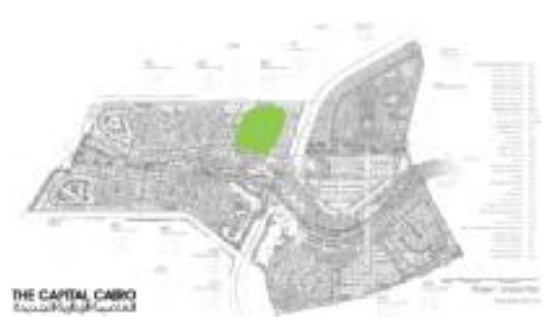

شكل (Y) الحي السكني الثالث بالعاصمة الادارية الجديدة/المصدر: المي السكي الثن capital cairo - residential zone 3 july2017- urban development و - consortium و المجتمعات العمر انية

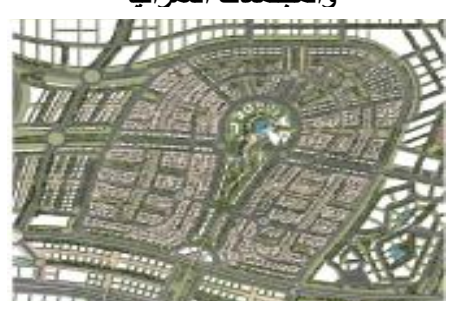

المناقشة : المر ب/ الاراسة التحليلية للتجمعاث السكنية: آس/ الثة دراسية : الحي السكني R3 بالعاصمة الادارية الجديدة في مصر: ا - ان الحى السكنى رقم ب هو اول حى تم تم بدء العمل فيه

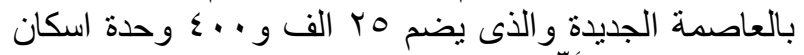
وو حدات تجاصنة الجيدة -تنوعت المناطق السكنية في الكثافة، جميعها احتل مناطق مميزة جغر افيا ومناخيا، وسط مساحات خضر اء و وأنظمة مستدامة ومتجددة لتوليد الطاقة وتدوبر المخلفات وتحلبة المباه 35

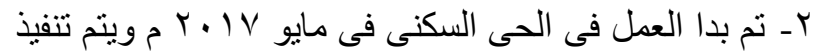

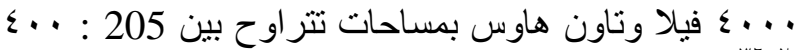

$$
\text { شكل (r) الحي السكني الثالث بالعاصمة }
$$

الادارية الجديدة/المصدر: Capital residence r t

- the capital cairo - residential zone 3

july2017- urban development

consortium

$$
\text { والمجتمعات العمرانية }
$$




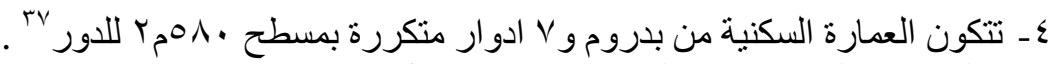

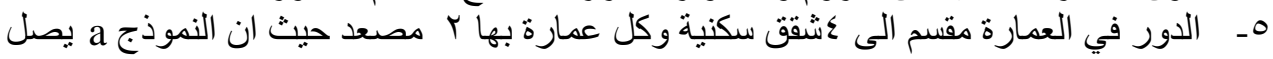

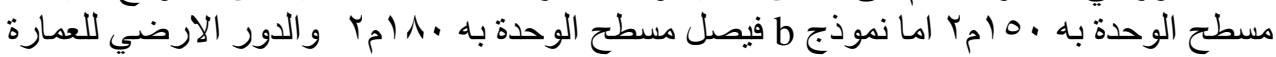

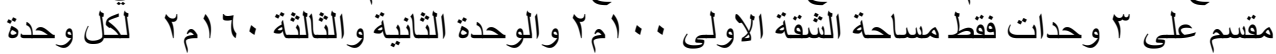

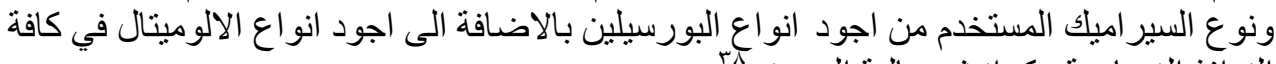

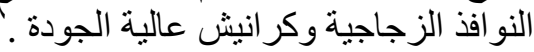

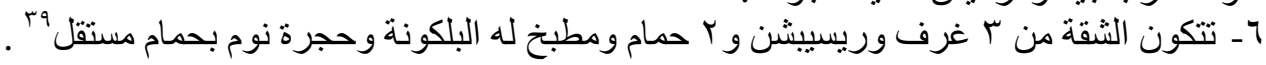

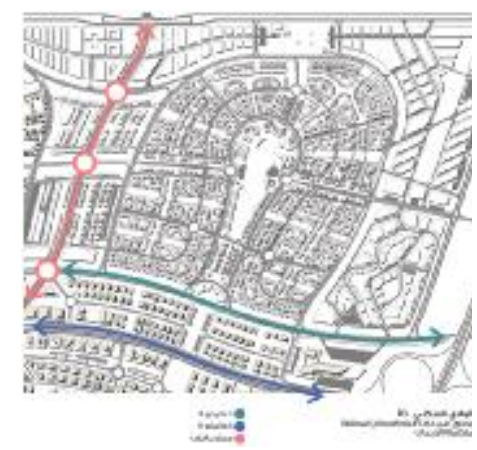

شكل (0) مسارات النقل الجماعي

بالحي السكني الثالث / المصدر:

Capital residence - the capital

cairo - residential zone 3

july2017- urban development

consortium

والمرافق والمجتمعات العمرانية

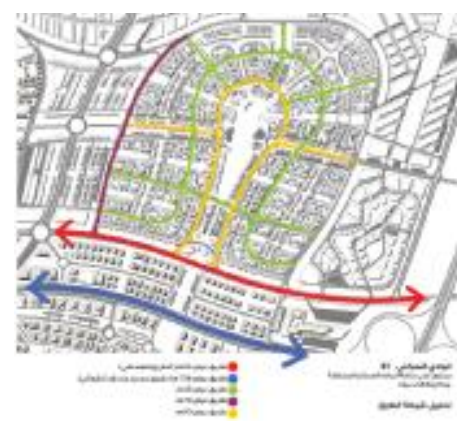

شكل (ء ) شبكة الطرق بالحي السكني الثالث

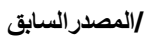

N- - تسعى شركة العاصمة الادارية لو

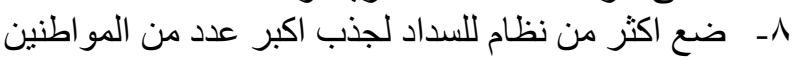

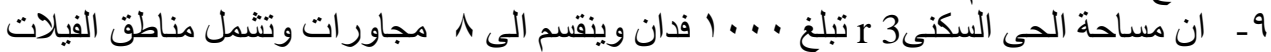

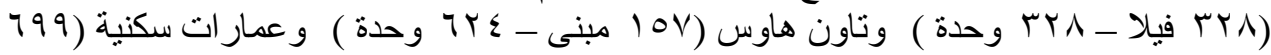

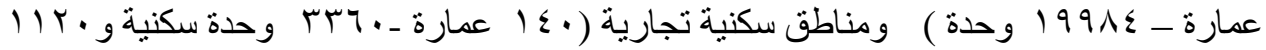

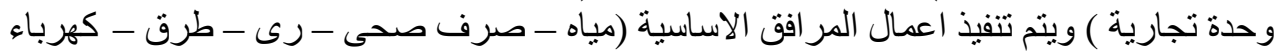
• ـ ـ الحى السكنى سيكون عبارة عن مدينة منكاملة الخدمات تتضمن مر اكز شباب ومدارس دولية ومدارس خاصة وكافة الخدمات المطلوبة التى تتطلبهار مانها الحياة السكنية 
THE SMART SUSTAINABLE COMPOUNDS (STUDY CASE: THE NEW ADMINISTRATIVE CAPITAL IN EGYPT)

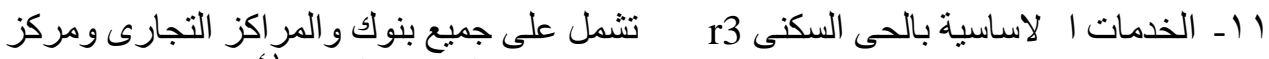

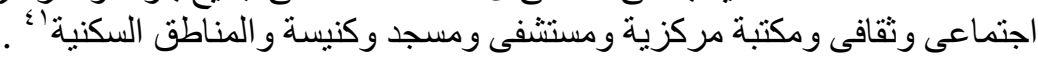

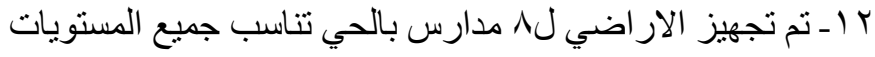

\section{r/r الاشتراطات البنائية بالقطاع السكني بالمرحلة الاولي:

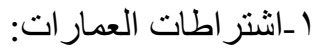

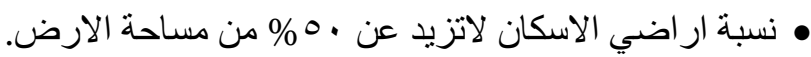

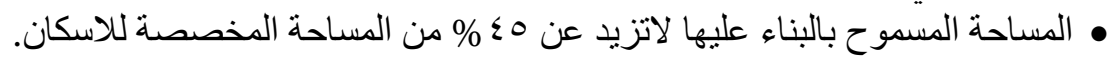

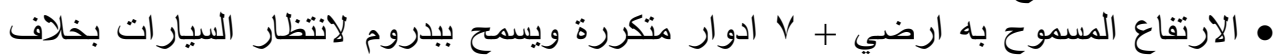

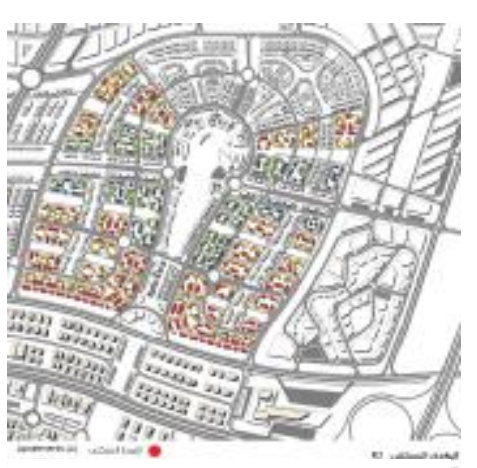

شكل (") الانماط الاسكانية المختلفة بالحي السكني الثالث /المصدر السابقة المابق

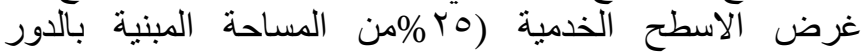
الارضي ) على ان يتم الالتزام بقيود الارتفاع المفروضة من قلئل

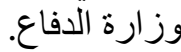
• المسافة بين عمار ات المشروع واع وفيلات اي مشروع مجاور ان

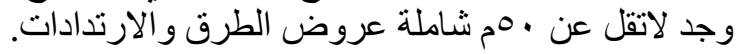

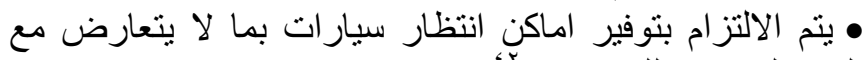

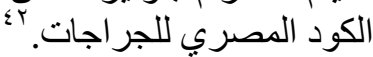

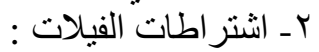

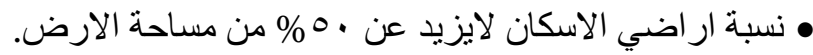

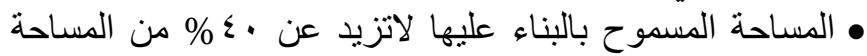
المخصصة للاسكان. • الارتفاع المسموح به ارضي + دور اول + بدروم لانتظار السيارات

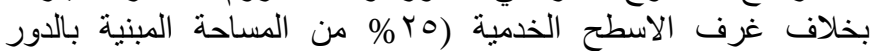

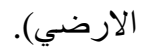
• • الكثافة السكانية بحد اقصى 0 ؛ شخص /فدان.

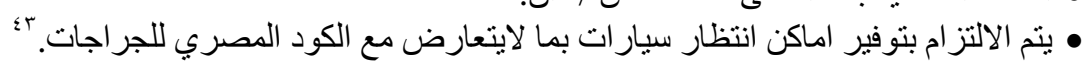

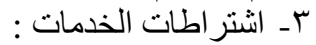

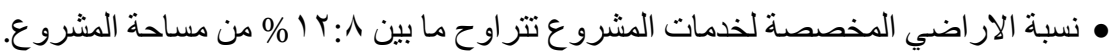

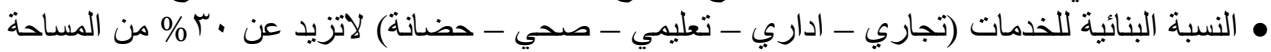

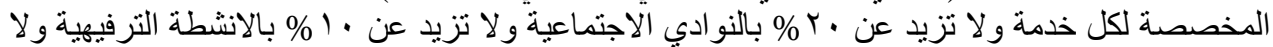

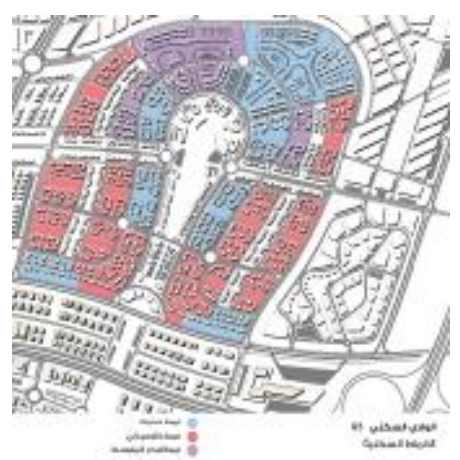

JAUES, 14, 52, 2019
تزيد عن 0\% بالنو ادي الرية الرياضية • ينم الالتزام بتوفير اماكن انتظار سيارية الرئ طبفا للكود المصري

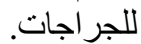
• يتم الالتز ام بتحقيق ارتدادات تبلغ 7 م من جميع الاتجاهات.

شكل (V) المجاورات بالحي السكني الثالث / المدر /

Capital residence - المصدر: المصني (لمدرات

the capital cairo - residential zone3 july2017- urban

الاسكان والمرافي وزارة development consortium

الاسكان و المر افق والمجتمعات العمرانية 


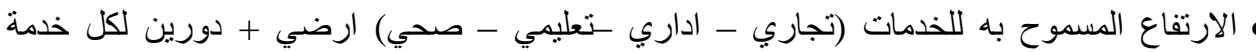

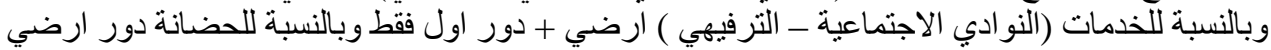

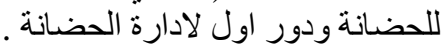

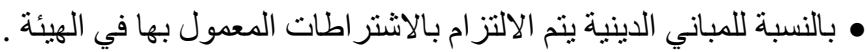

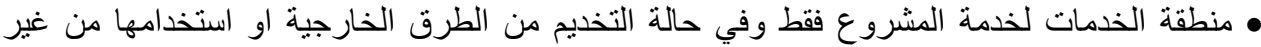

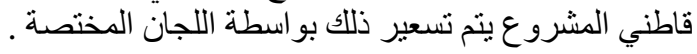

• يتم الالتزام بقيود الارتفاع المحددة من قبل وزارة الدفاع بما لايتجاوز الاشتراطات البنائية

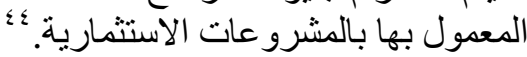

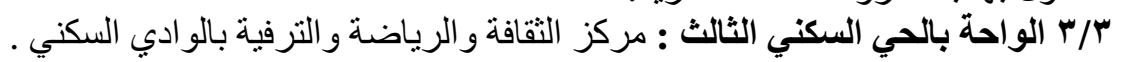

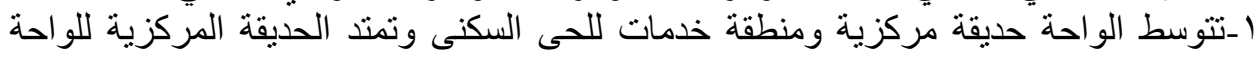

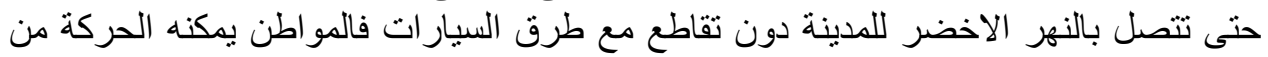

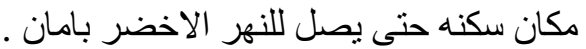
ץ-وقد تم تخطيط وتصميم الواحة ومبانى الخدمات لتحقيق السبعة مبادىه الحانه الحاكمة لتخطيط

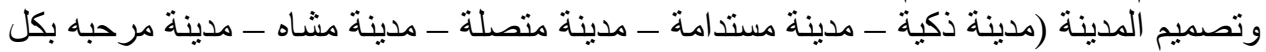

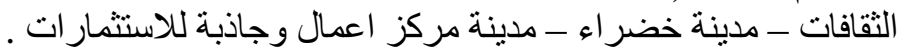

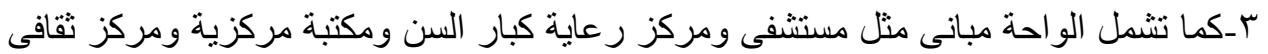

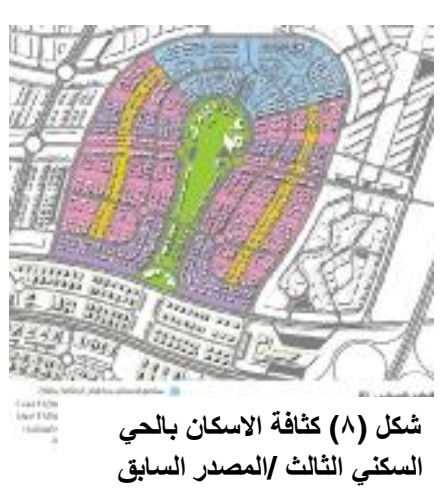

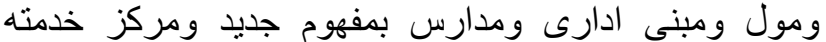

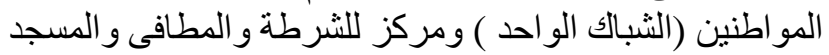
و الكنيسة ونادى اجتماعى ومركز تحكم الخدمات الذئس الذكية ومنطقة

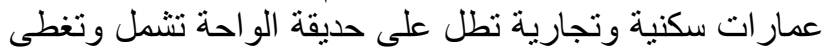

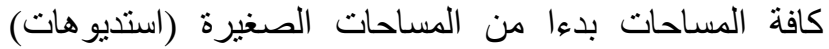

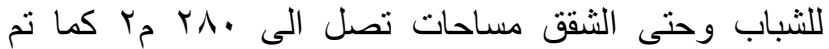

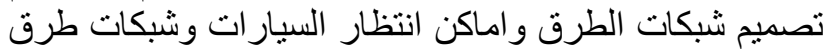

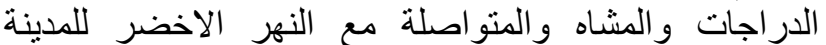

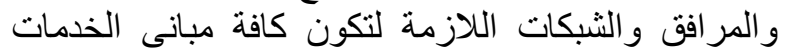
ذكية وموفرة للطاقة باستخدام الطاقة الشمسية وشيكات

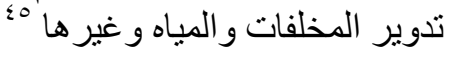


THE SMART SUSTAINABLE COMPOUNDS (STUDY CASE: THE NEW ADMINISTRATIVE CAPITAL IN EGYPT)

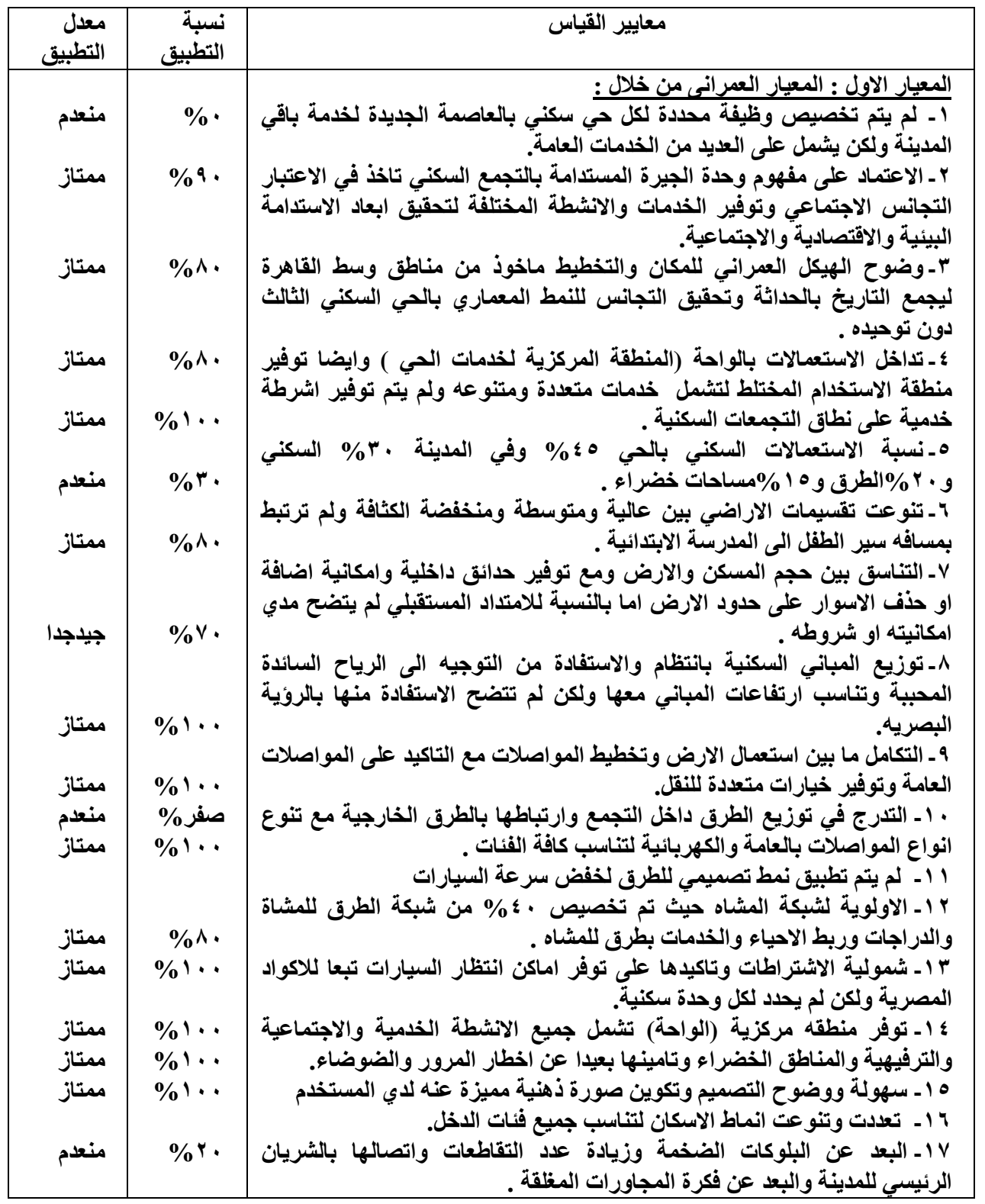


THE SMART SUSTAINABLE COMPOUNDS (STUDY CASE: THE NEW ADMINISTRATIVE CAPITAL IN EGYPT)

\begin{tabular}{|c|c|c|}
\hline ممتاز & $\% 1 \ldots$ & 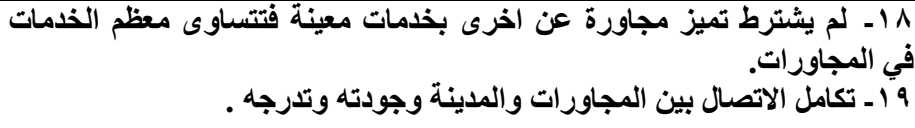 \\
\hline & & المعيار الثانى : المعيار البيئى من خلال : \\
\hline جيا & $\%^{\circ}$. & 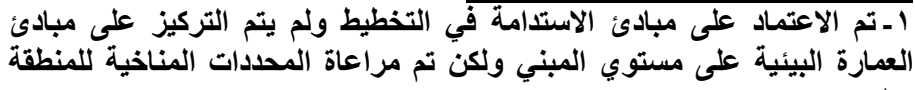 \\
\hline 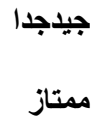 & $\% v$. & 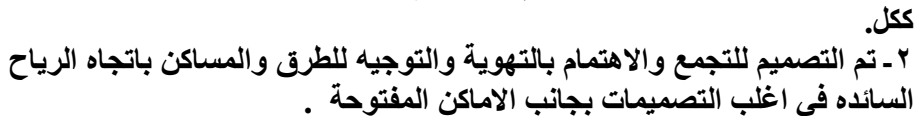 \\
\hline ممتاز & $\% 9$. & 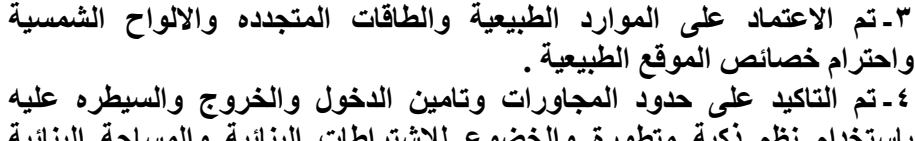 \\
\hline ممتاز & $\% 9$. & 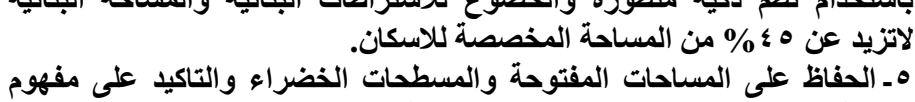 \\
\hline جيذجدا & $\% \wedge 0$ & 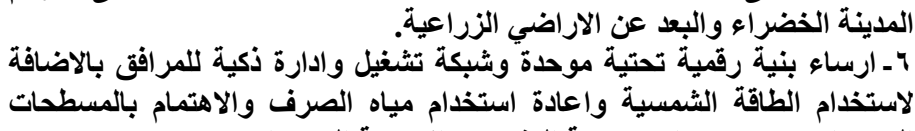 \\
\hline جيد & $\% 0^{\circ}$. & 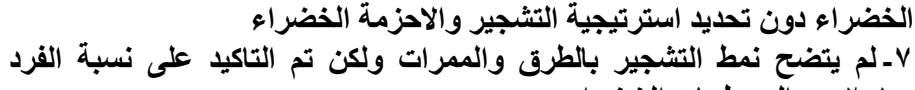 \\
\hline ممتاز & $\% 1 \ldots$ & 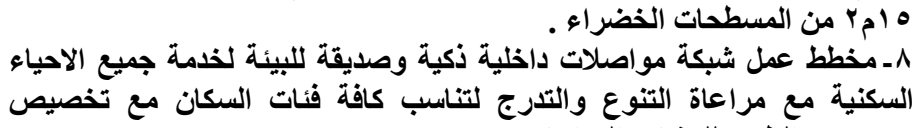 \\
\hline ممتاز & $\% 1 \cdots$ & 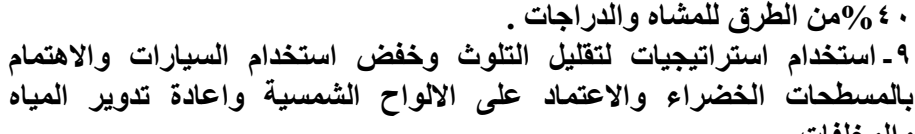 \\
\hline جياجدا & صفر \% & 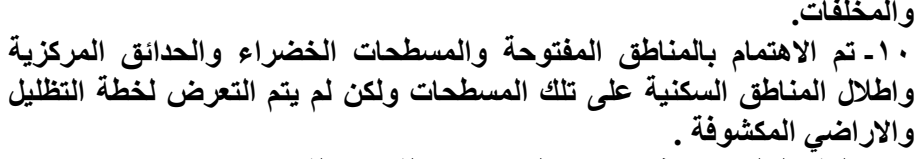 \\
\hline 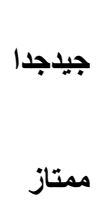 & $\% \vee \cdot$ & 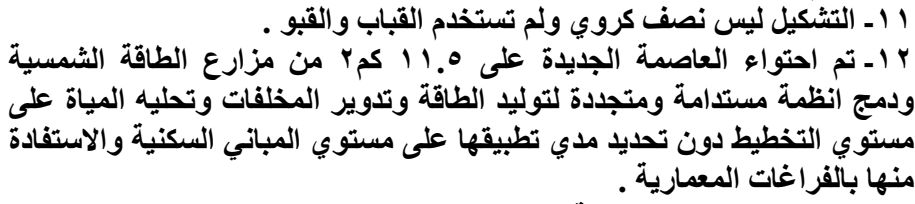 \\
\hline جياجدا & $\%$ & 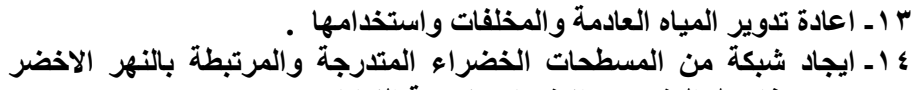 \\
\hline ممتاز & $\%^{\wedge}$. & 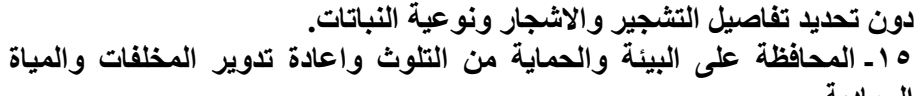 \\
\hline جياجدا & $\% \vee \cdot$ & 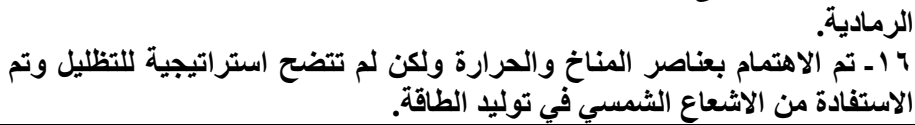 \\
\hline
\end{tabular}


THE SMART SUSTAINABLE COMPOUNDS (STUDY CASE: THE NEW ADMINISTRATIVE CAPITAL IN EGYPT)

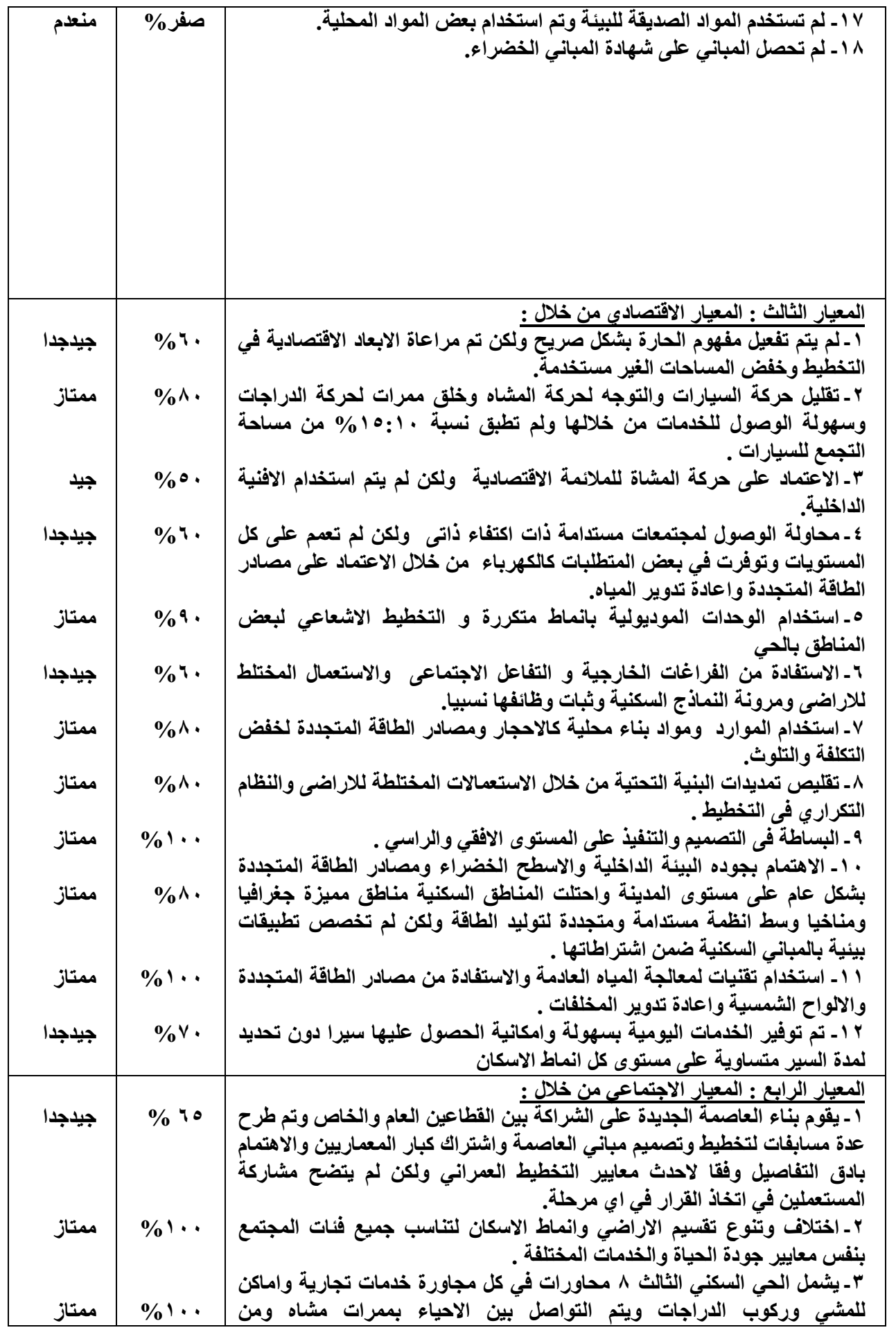




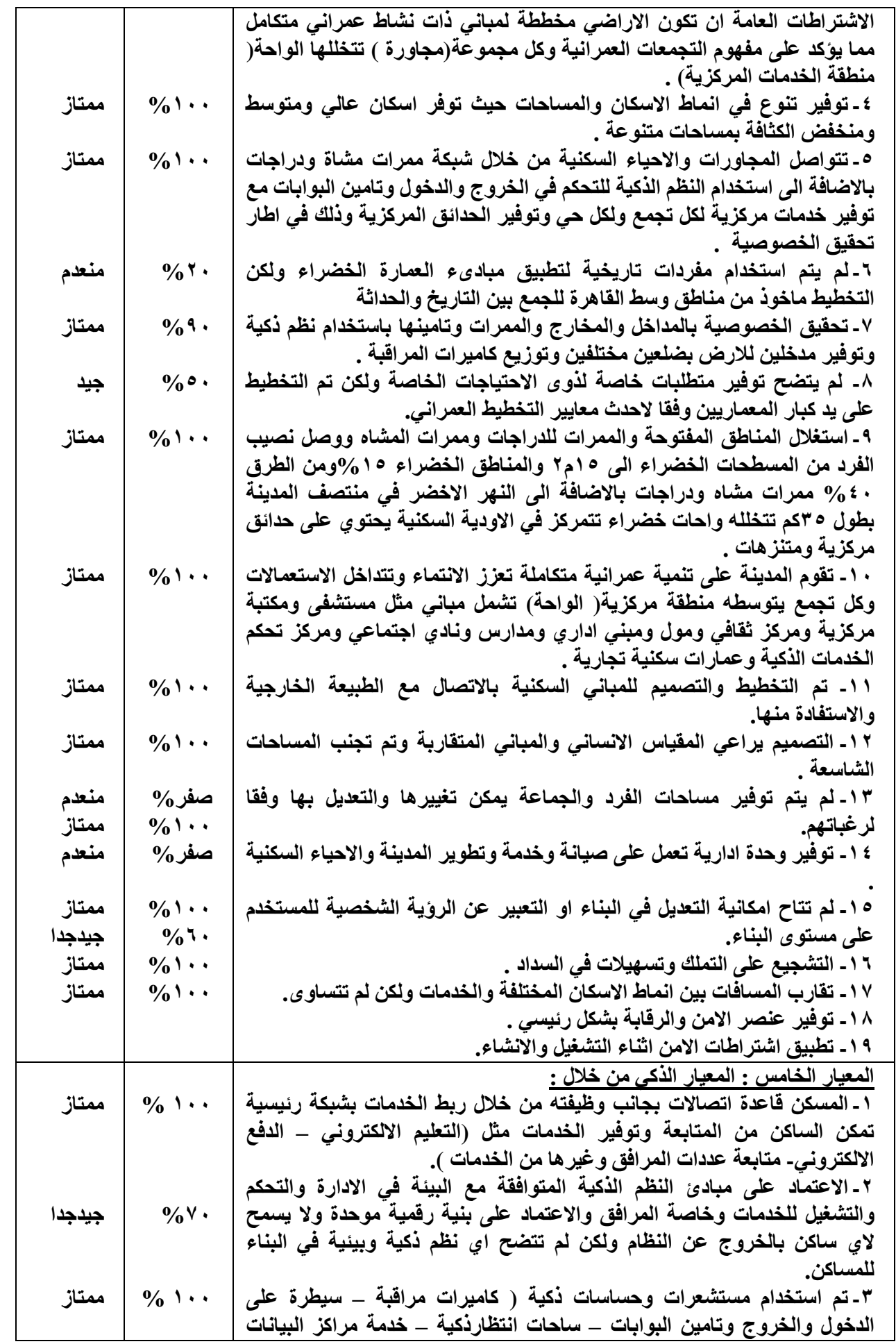



IN EGYPT)

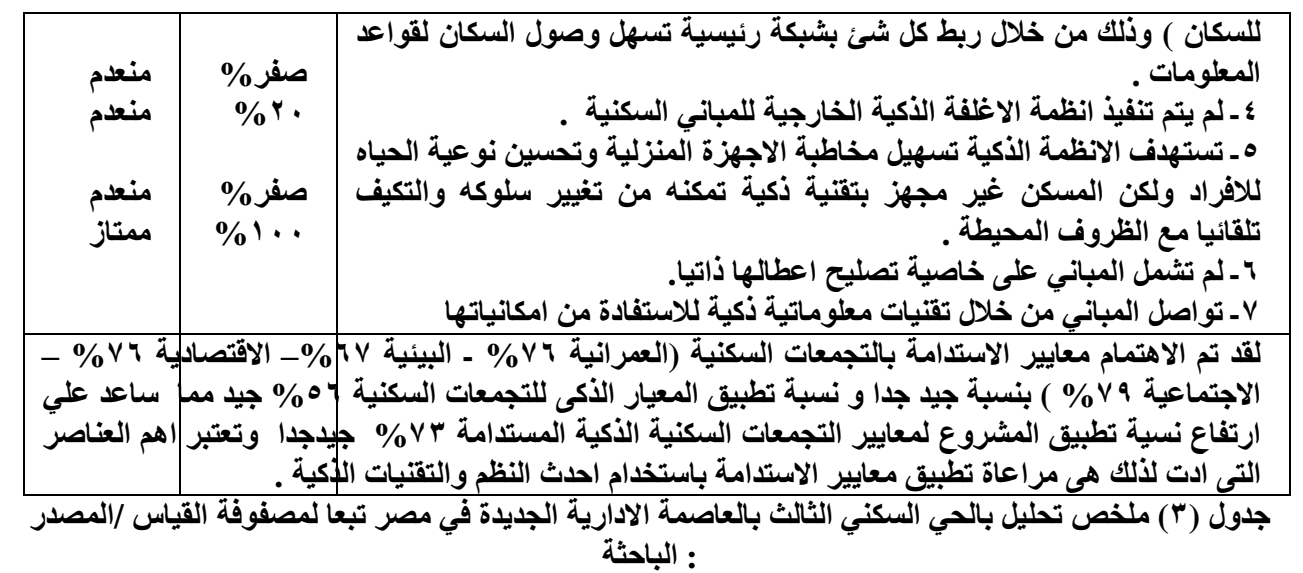

نقاط القوة بالمشروع:

1. اعتماد مفهوم وحدة الجير المستدامة واقامة تمبرة تمبية عمر انية متكاملة صديقه للبيئة من خلال تطبيق اشتراطات عامة ونسب استعمالات تتطابق مع معظم معايير الاستدامة والتوجهات التخطيطية الحديثة.

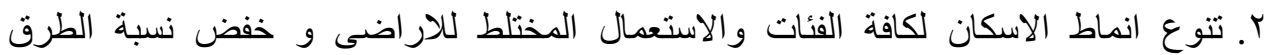

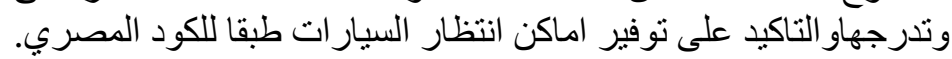

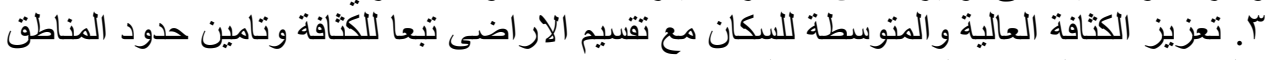

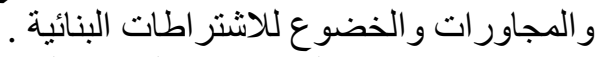

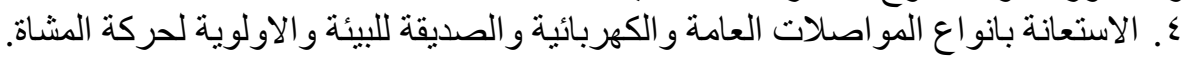

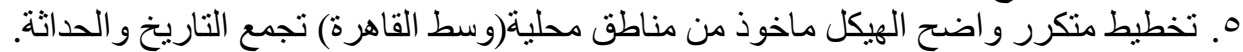

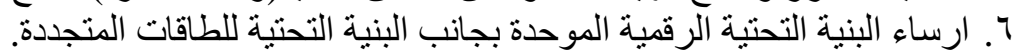

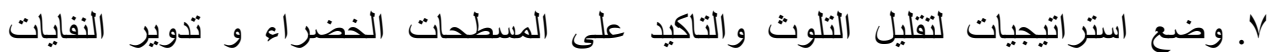

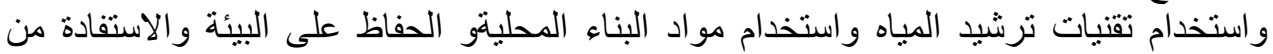
العناصر المناخية وتوظيفها (الاشعاع الثناع الثمسيدي).

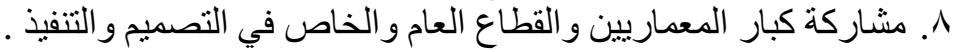

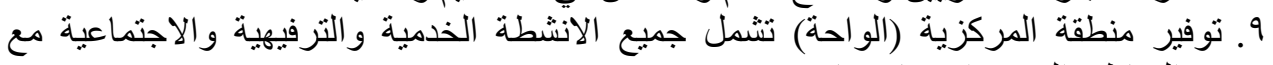

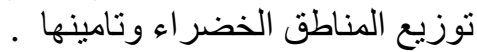

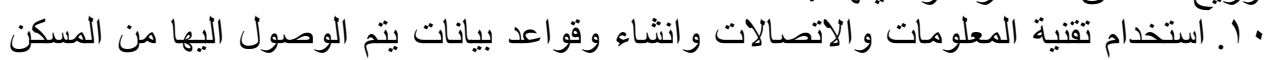
وتو اصل المباني مع بعضها لتحقيق اقصى التصى استفادة. 1 ا ـ استخدام محو لات بيانات ونظم ذكية منو افقة مع البيئة في التامين و الادارة و التشغيل للخدمات

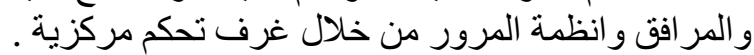

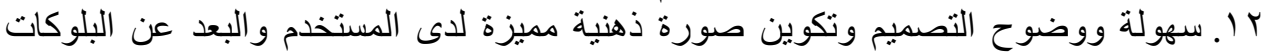
الضخمة و المساحات الثاسعة.

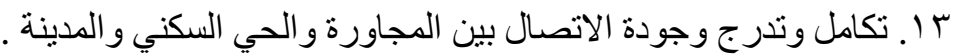

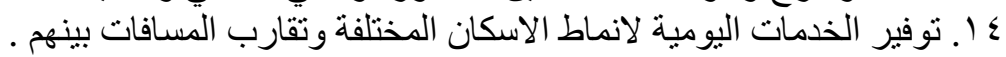

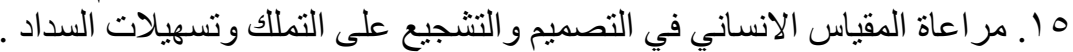

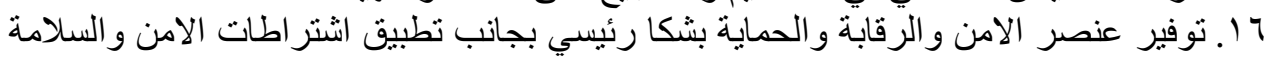

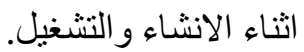


THE SMART SUSTAINABLE COMPOUNDS (STUDY CASE: THE NEW ADMINISTRATIVE CAPITAL IN EGYPT)

\section{نقاط الضعف بالمشروع:

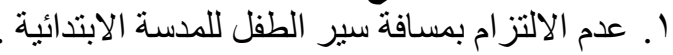

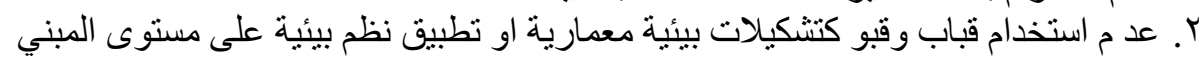

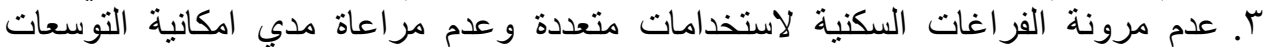

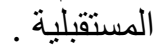

ع. لم يتضح المشاركة المجتمعية للمستعملين فى اتخاذ القرار ات التخطيطية .

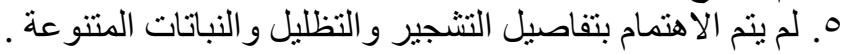
7. عدم تطبيق نظم ذكية سو اء الاعلفة الخارجية الذكية او للتحكم فى المسكن واستجابة التئنة التلقائية

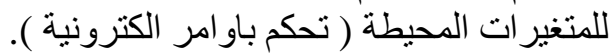

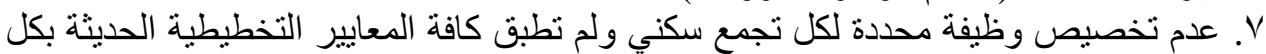

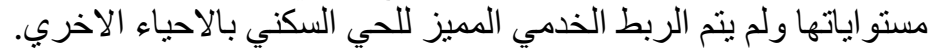

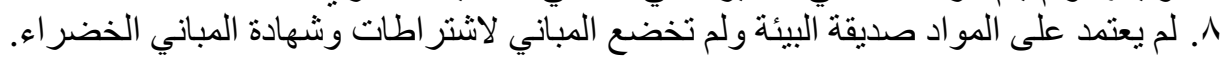

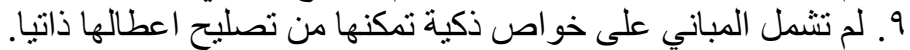

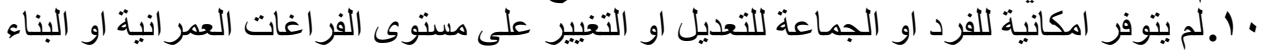

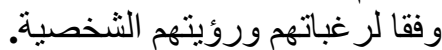

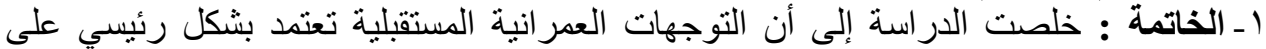

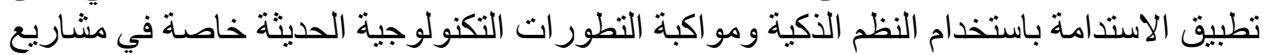

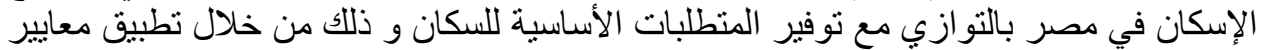

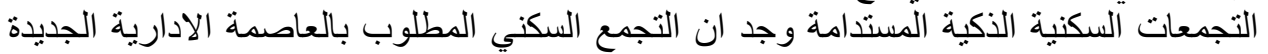

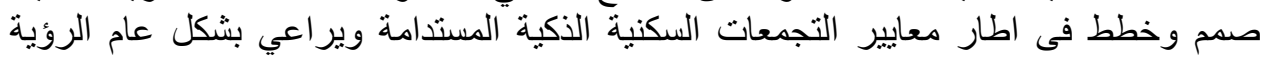

المستقبلية للعمران فى مصر والقائمة على تطبيق الاستدامة و النمو الذكى بالتجمعات العمر النية.

/ / النتائَج: (

ا ـ . على ضوء الدار اسة التحليلية للمشروع تم الوقوف على نقاط القوة التي حققت التخطيط الذكي

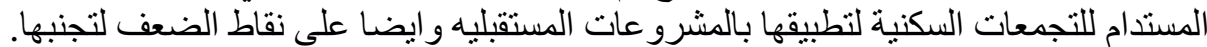

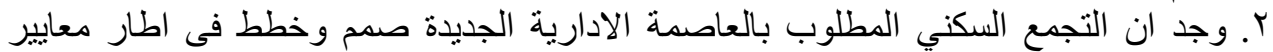

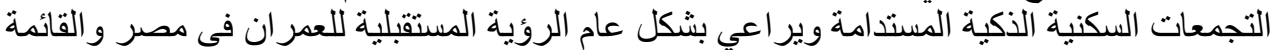
على تطبيق الاستدامة و النمو الذكى بالتجمعات العمر انية.

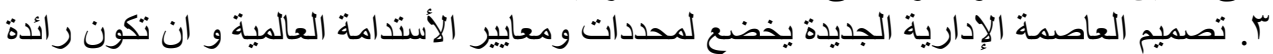

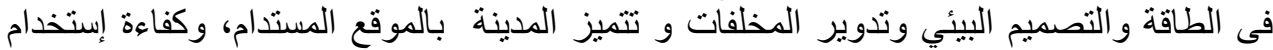

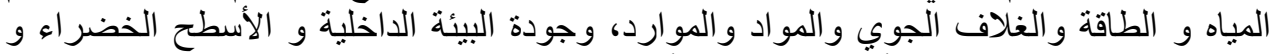

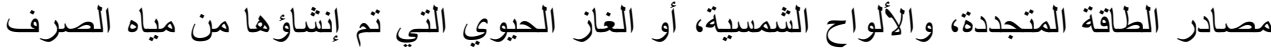
الصحي او المخلفات. عـ التوجه العام بالعاصمة الإدارية الجديدة تطبيق انظمة الحكومة الالكترونية والادارة الذكية

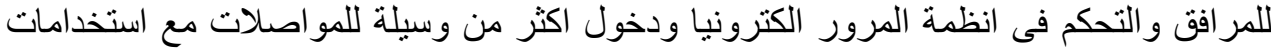

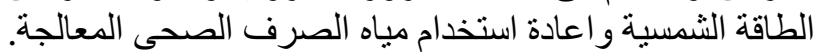
ع. الرؤية المقترحة للاسكان ف مصر تعتمد على تطبيق الاسكان الذكي المستدام كنموذج اسكاني

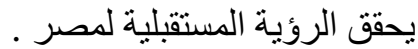

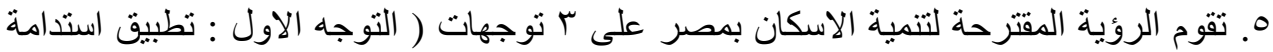
الاسكان بالتجمعات العدر انية الجديدة - التوجه الثاني: تطبيق الاقتصادية بالاسكان وتحقيق العلى JAUES, 14, 52, 2019 
عائد نفعي ومادي منه - التوجه الثالث : نهيئة مناخ الاستثمار في مجال المنتج الذكي والنظم

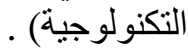

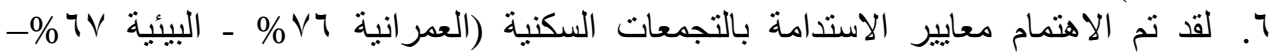

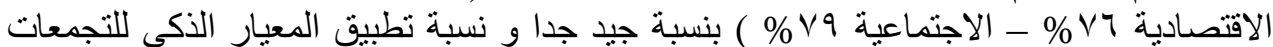

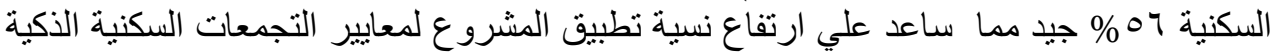

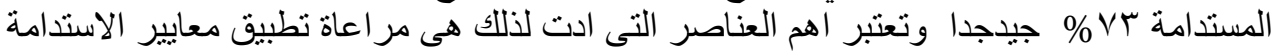
باستخدام احدث النظم و التقنيات الذئنة V.يتعلق مدي نجاح التجمعات السكنية وتحقيقها للاهداف المرجوة بمدى تطبيق معايير الاستدامة واستخدام

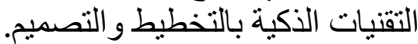

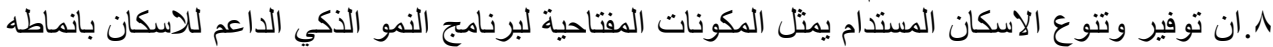

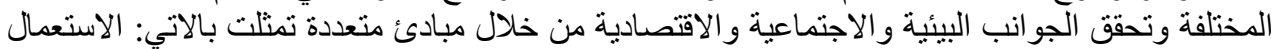

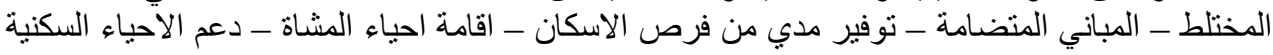

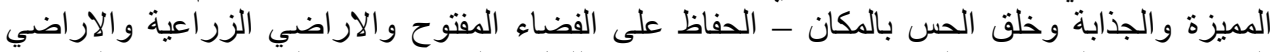

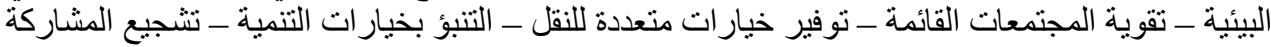

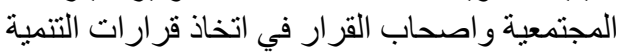

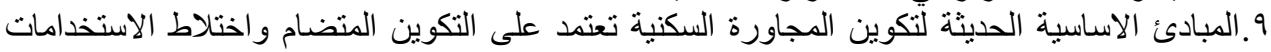

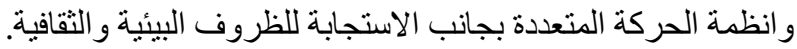

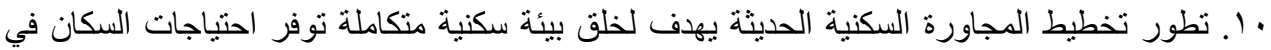

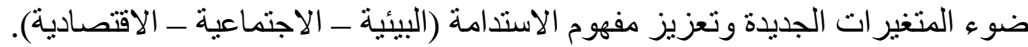

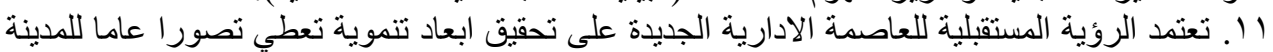
في المستقبل وتعنمد على تحقيق مبدا الاستدامة.

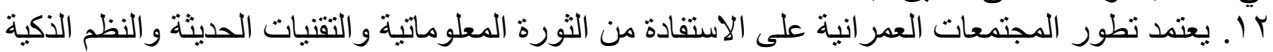

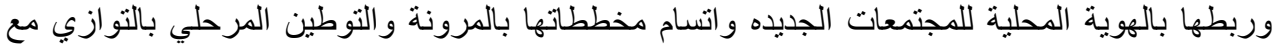

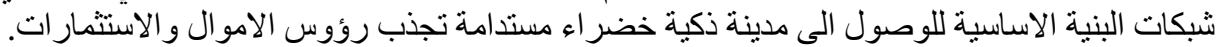

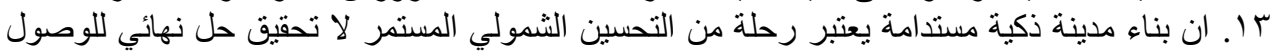

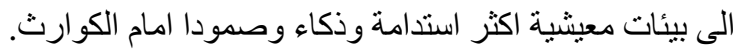

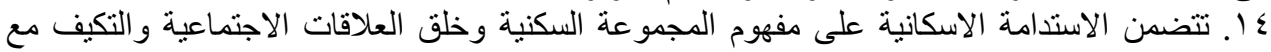

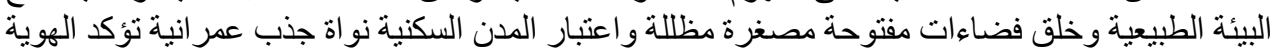
الحضرية.

\section{ع/ آلتوصيات الابحاث المستقبلية:}

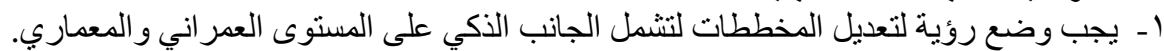

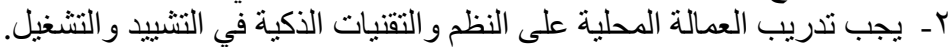

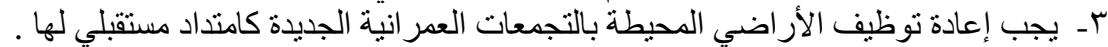

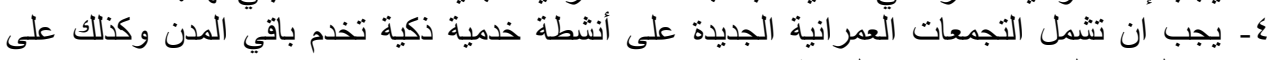
مستوى التجمع السكني يخدم باقي المدينة.

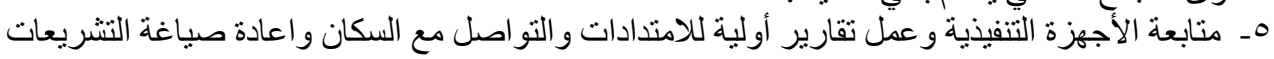

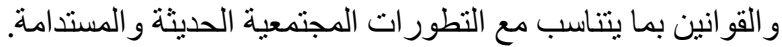

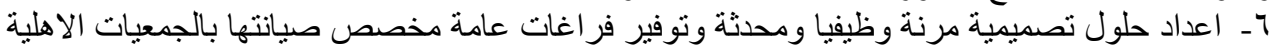

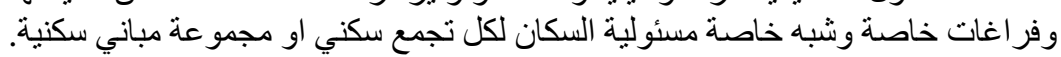

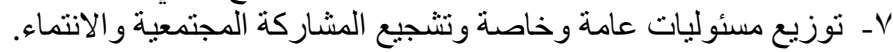

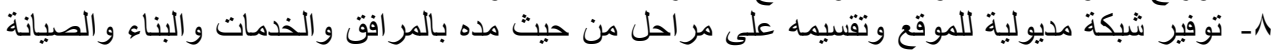
و المتابعة. 


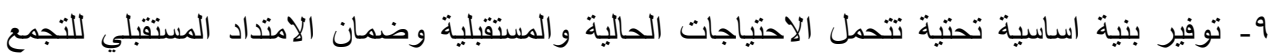

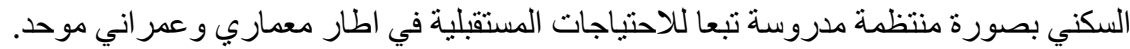

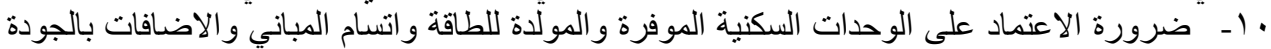

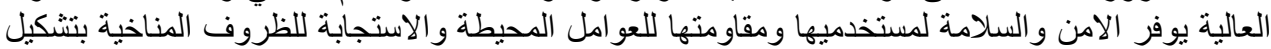
معماري يعبر عن الهوية المحلية.

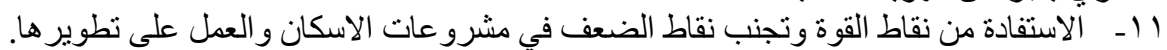

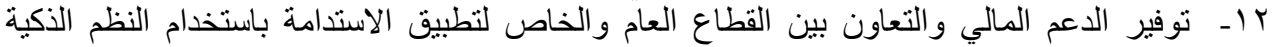

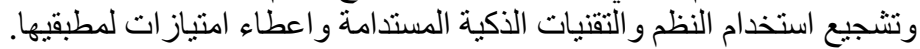

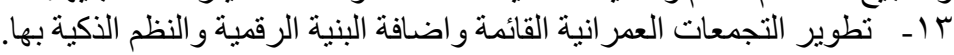

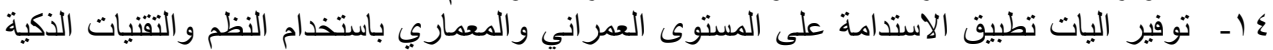
والرقمية قياس مدى تطبيق المشروعات للمعايير السكنية الذكية المستدامة ونو افق المخطط المنات العمر انية مع 1ا - ـ تطوير مناهج التعليم المعماري ليتضمن بشكل رئيسي التطورات التقنية الذكية وكيفية دمجها

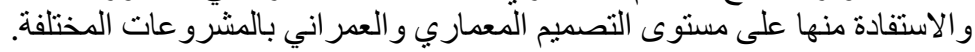
المراجع

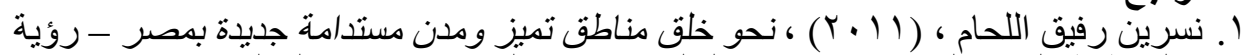

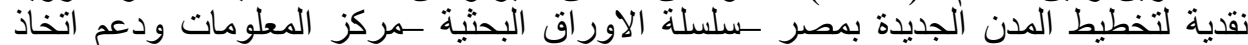

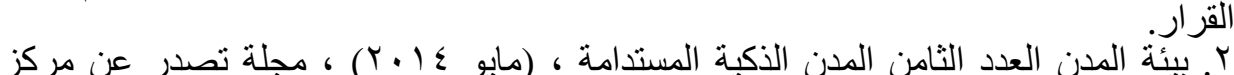

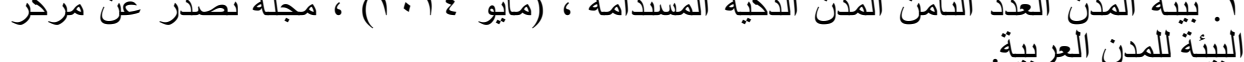

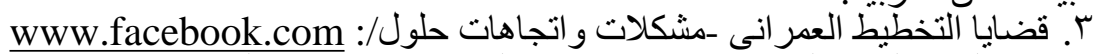

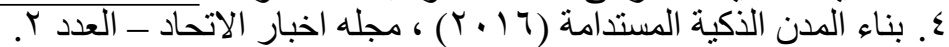

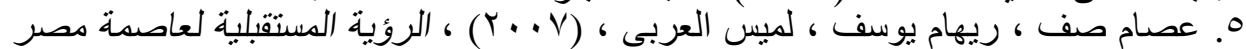

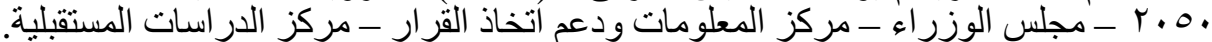

6. https://newcapitaltoday.blogspot.com.eg/2017/07/newcapitalegypt _30.html

8. Capital residence - the capital cairo - residential zone3 july2017-

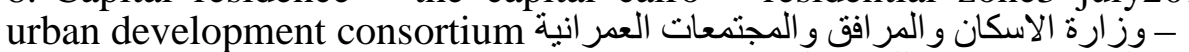
9. شركة العاصمة الادارية للتنمية العمر انية العبانية https://Www.facebook.com/acudegy/posts

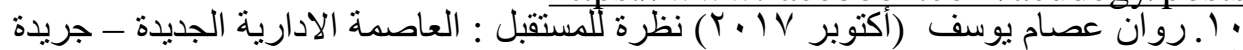

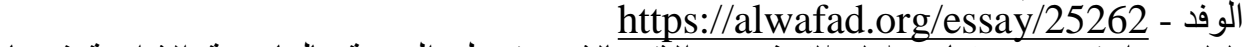

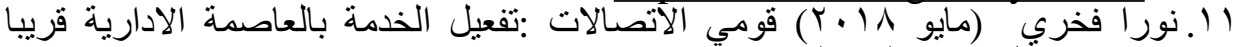

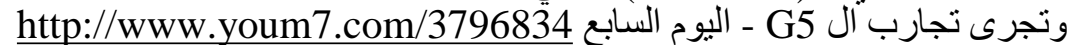

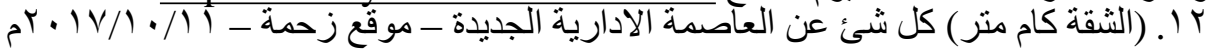
https://zahma.cairolive.com با..وزير الاسكان يكثف اسباب انشاء العاصمة الادارية الجديدة - دوت دمكر مصر

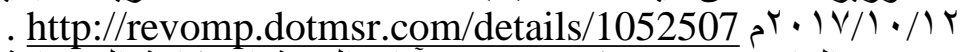

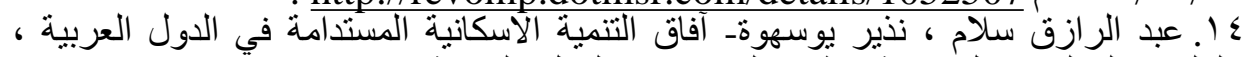

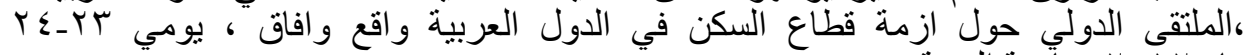

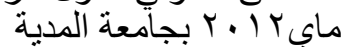

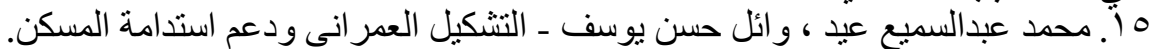

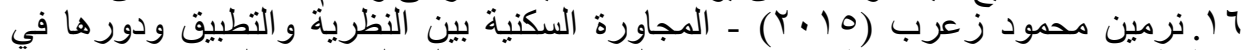
تخطيط مشاريع الإسكان في قطاتع غزة - رسالة ماجستير - كلية الهندسة - الجامعة الاسلامية الطية. 


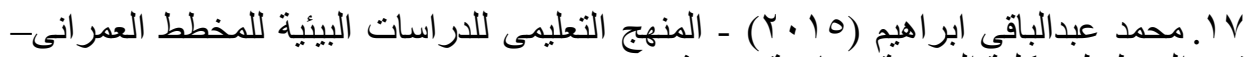

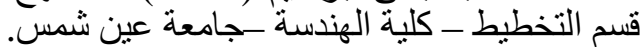

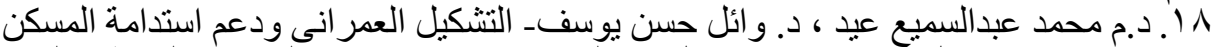

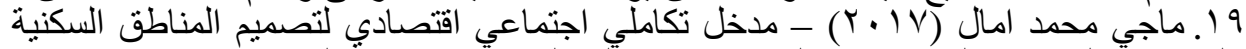

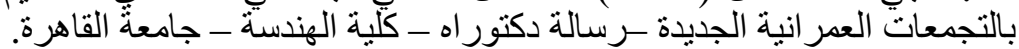

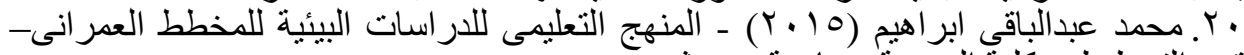

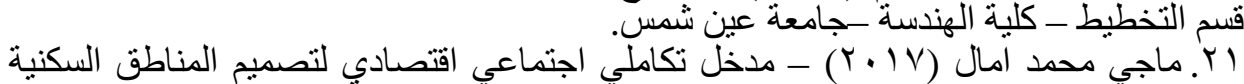

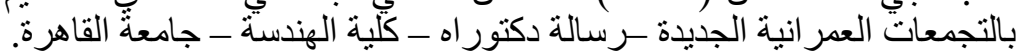

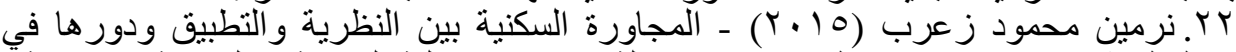

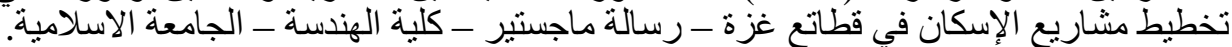

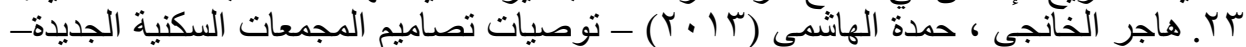

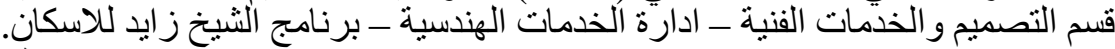

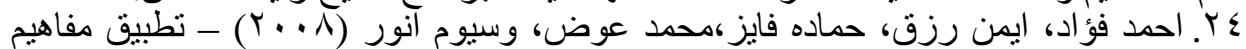

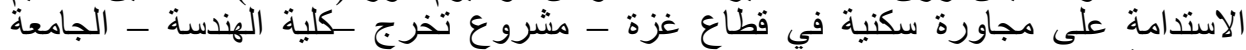
الاسلامية.

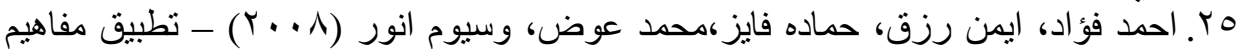

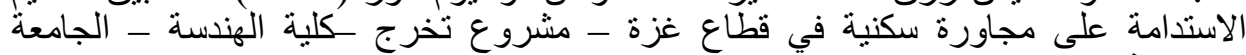
الاسلامية.

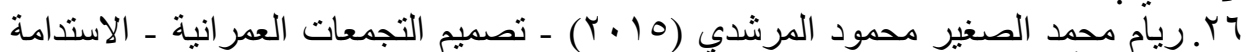

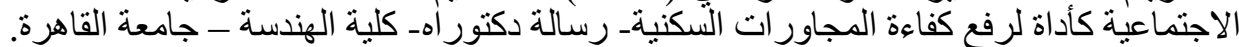

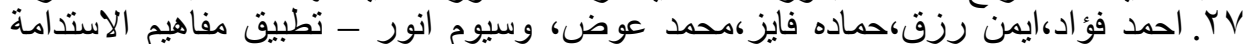

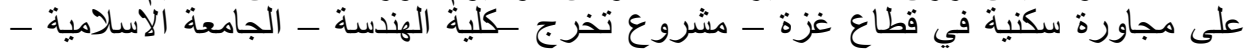

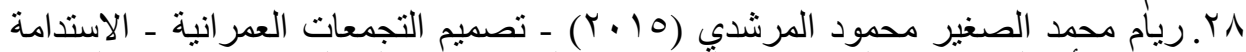

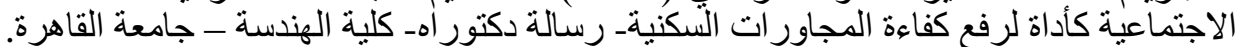

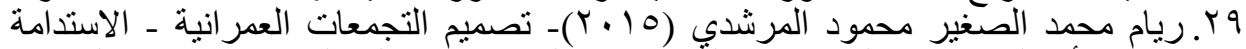

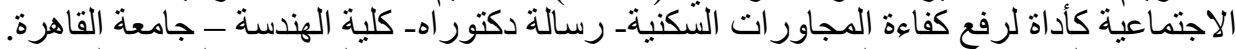

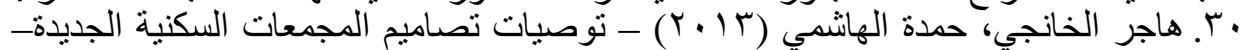

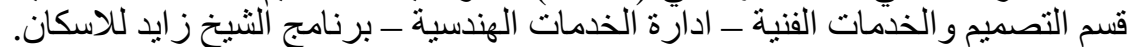

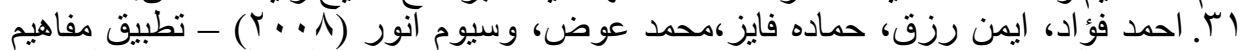

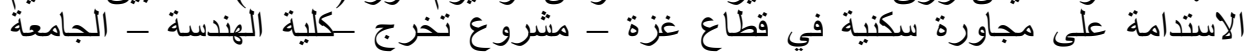
الاسلامية.

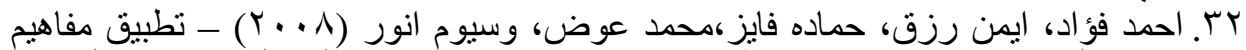

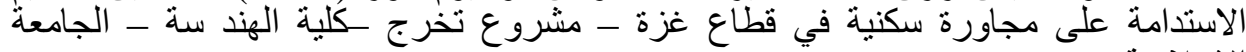
الاسلامبة.

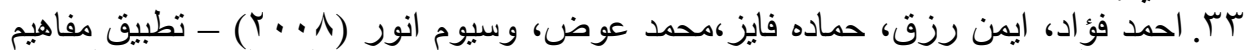

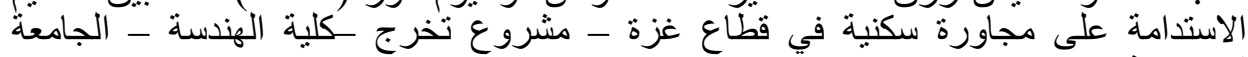
الاسلامية.

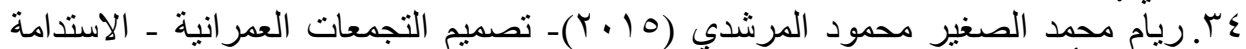

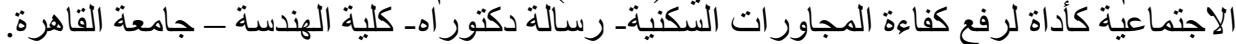

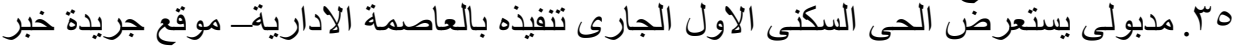

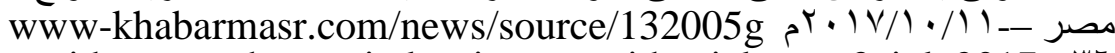
Capital residence - the capital cairo - residential zone3 july2017- ד -urban development consortium وز ارة الاسكان والمر افق والمجتمعات العمر انية 


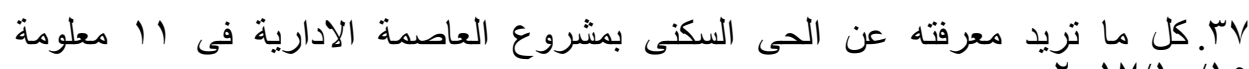
http://new http://new capitaltoday.blogspot.com.eg/2017/new capitalegypt-.r^ 11.html وب. كل ما تريد معرفته عن الحى السكنى بمشروع العاصمة الادارية فى ال 11 معلومة http://new capitaltoday.blogspot.com.eg/2017/new capitalegypt- • 11.html

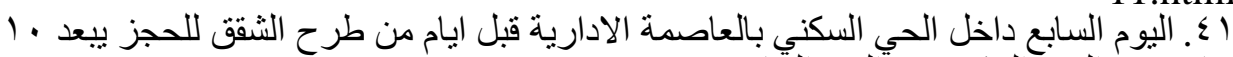

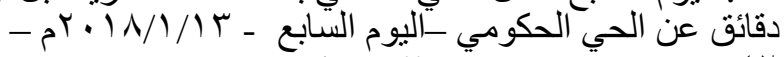
http://Www.youm7.com.. r

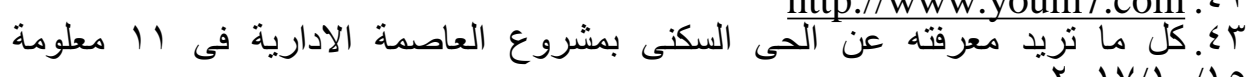
http://new capitaltoday.blogspot.com.eg/2017/new capitalegypt- . $\leqslant \varepsilon$ 11.html ه؛. موقع جريدة النبا-ننشر التفاصيل الكاملة للحى السكنى بالعاصمة الادارية الجديدة

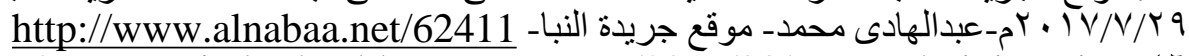
http:/new capitaltoday.blogspot.com.eg/2017/03/new administrative . capital 10.html

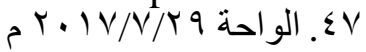
http://newcapitaltoday.blospot.com.eg/2017/03/newadministrativecap ..$\wedge$ ital-17.html 